\title{
ICEM-96 Joins 1996 MRS Fall Meeting
}

The 1996 MRS Fall Meeting was joined this year by the International Conference on Electronic Materials (ICEM), a biennial conference sponsored by the International Union of Materials Research Societies (IUMRS). The ICEM element of the program brought into focus the electronic aspects of the meeting and encouraged expanded international involvement by having many non-U.S. symposium organizers. The meeting held December $2-6$ in the Boston Marriott Hotel, Westin Hotel/ Copley Place, and the Sheraton Boston Hotel attracted over 4,300 attendees to over 3800 oral and poster presentations in 34 technical topical symposia plus Symposium X, Frontiers of Materials Research, and a workshop on materials education (Symposium JJ). The meeting was chaired by Werner Lutze (University of New Mexico), Karen Maex (IMEC), and Karl Sieradzki (Arizona State University).

John P. McTague, Vice President of Technical Affairs at Ford Motor Company gave the plenary presentation Monday evening, "Where in the World is Science and Technology Going?" He first looked back to examine earlier predictions of today's world, and then looked to the future, where he expects globalization to guide the direction of science and technology. Other events included the awards ceremony, a public affairs forum, an IUMRS forum on policies and plans related to the future of materials research and education in the global community, a junior faculty forum, and several careerrelated activities. In addition, an exhibit of products and services complemented the meeting. See sidebars for more information on these events.

Symposium $X$, Frontiers of Materials Research, presented an eclectic set of topics of interest to the nonspecialist. David J. Smith (Arizona State Univ.) described advances in the electron microscope such as high-voltage high-resolution techniques, electron holography and nanospectroscopy, high-angle annular darkfield imaging in the STEM, energy-filtered imaging and diffraction, and digital image recording and processing. Nuclear issues entered into two presentations, one by Wolfgang Stoll on options for disposition of excess weapons plutonium and the other given by Evgeniy B. Anderson, V.G. Khlopin Radium Inst. MINATOM, St. Petersburg, Russia on the 4th unit of Chernobyl, showing the problems still plaguing the site. This year is the 10 th anniversary of the nuclear accident at Chernobyl. Pierre-Gilles de Gennes, Professor at the College de France in Paris, Director of the School of Physics and Chemistry of Paris, and 1991 Nobel Prize Laureate in physics, reflected on the evolution of polymer materials and highlighted "dubious battles" in polymer science in an entertaining but insightful presentation. He is skeptical that computers will operate with molecular-chain wires. While molecular chains have been achieved, $10^{9}$ operations repeated on that one thread would mean bringing it to a highly oxidized state and then reducing it $10^{9}$ times without a chemical reaction taking place that would burn it to pieces. Also doubtful, he said, are ferromagnetoelastomers at the atomic scale, self-healing materials that begin to fracture and then close up by release of a monomer that polymerizes, and magic batteries to power cars as efficiently and cost-effectively as conventional cars. Other talks covered the electrical resistance of a carbon nanotube, nanophase materials, metallic glasses, and metallic corrosion.

In Symposium $N$ on III-V nitrides $S$. Nakamura (Nichia Chemical Industries), in a presentation attended by 430 scientists, announced the fabrication of InGaN multiquantum-well violet laser diode capable of $\mathrm{cw}$ operation at room temperature with $35 \mathrm{~h}$ lifetime. In addition to reports of device performance, many presentations focused on growth methods, for instance, the sublimation method, MOCVD, and MBE. Theoretical arguments for phase separation in InGaN alloys and ordering in AlGaN alloys were also presented.

In Symposium O, long wavelength detectors and sources as well as nonlinear applications attracted the most attention. Results for IR lasers grown on an InAs substrate with wavelengths between 3.2 and $3.5 \mu \mathrm{m}$ have shown pulsed operation up to $225 \mathrm{~K}$. Lasers grown on GaSb substrates have operated pulsed up to $165 \mathrm{~K}$ and $\mathrm{cw}$ operation to $128 \mathrm{~K}$.

In the areas of electronic organic materials and fullerenes (Symposium D), fluorescence of polymers was presented and the lifetime of PPV-based LEDs was prolonged to about $1,200 \mathrm{~h}$ at initial and final luminous outputs of 100 and $50 \mathrm{Cdgm}^{2}$. The manufacturing technology required for future commercial products is emerging based on polymer LEDs. Advances in analyzing fullerene-related structures included tunneling experiments showing the local density of states in the nanoscale range, Raman spectroscopy to analyze the size distributions of single-wall nanotubes, and demonstration, for the first time, of the intrinsically metallic character of nanotubes.

Symposium $Q$ was devoted to the preparation, characterization, understanding, and application of polycrystalline films, nanocrystals, and porous semiconductors. A unifying theme was the modification of semiconductor properties resulting from electronic confinement.

Defects in electronic materials have an important role to play, as shown in Symposium E. A new ion-beam method was shown for quantitative depth profiling of

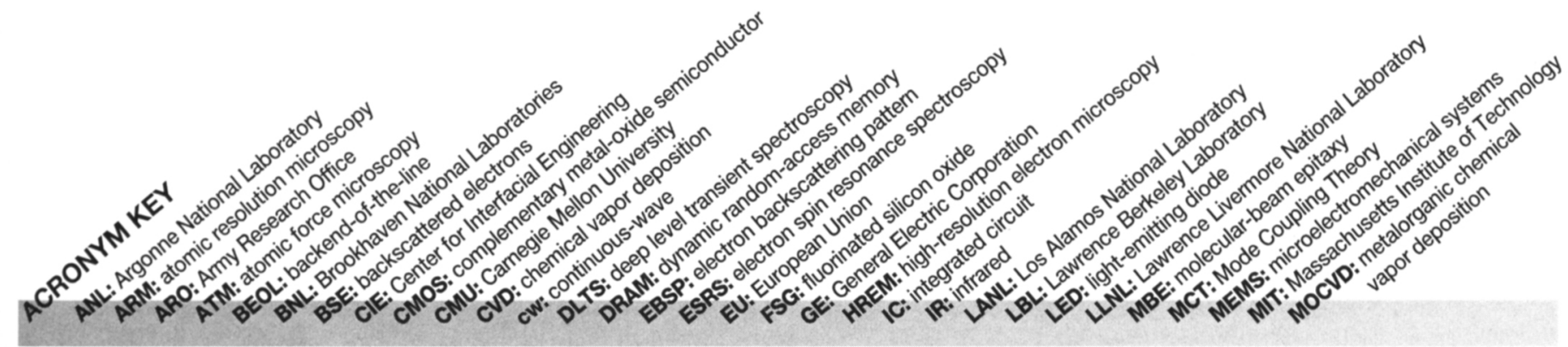


light impurities which may prove useful in developing standards for SIMS. A twobeam optical method for detecting microdefects near the surface of Si wafers may be useful in productions. STM pictures from cleaved surfaces of $\mathrm{GaAs}$ showed compensation of donors, resolving $\mathrm{Si}$ donors and acceptors, Si-pairs and clusters, and Ga-vacancies and Si-vacancy pairs.

A vast number of possible candidates to be used as low-dielectric constant materials, highlighted in Symposium $\mathrm{H}$, include organic layers like parylenes, polyimides or BCB deposited by spin-on, or CVD aerogels, or xerogels, amorphous carbon FSG. The lowest dielectric constants reported so far are those of the organic materials $(<2.5)$ and those of the air encapsulating materials $(<2)$.

Symposium $\mathrm{K}$ was devoted to research and development of thin dielectric films for optical and microelectronic applications. Apparently much of what was learned on thicker $\mathrm{SiO}_{2}$ films may not necessarily be transferable to the ultrathin regime $(<5 \mathrm{~nm})$. Some of the largest accomplishments have been in processing integration of complex oxides into standard Si CMOS processing lines and improved reliability.

Symposium A held joint sessions with Symposium B to examine critical microstructural issues pertaining to ion-beam processing of Si such as TED and defect/ damage behavior. The emergence of PII has been a big step forward for shallowimplant, large-area processing.

Symposium C, split into two symposia, emphasized surfaces and thin films. Symposium Ca contained experimental and theoretical studies of semiconductor, metal, ceramic, polymer, and self-assembled surfaces. The mechanisms and evolution of roughness received special attention, as did the structure and kinetics of thin-film surfaces. Symposium $\mathrm{Cb}$ focused on novel energetic growth processes, thin-film silicides and metallization, and the role of stresses in the

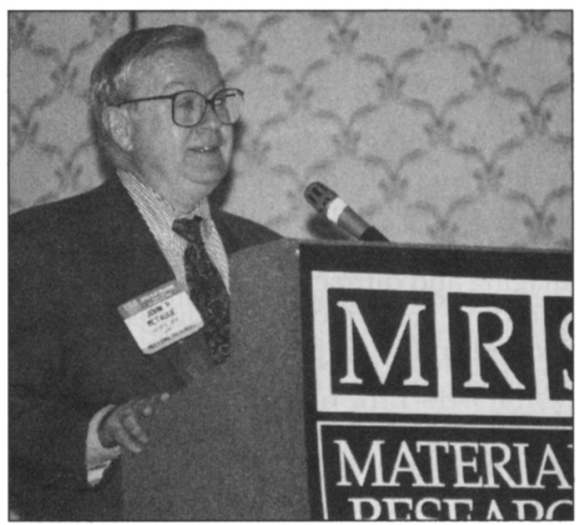

John P. McTague, vice-president of technical affairs at Ford Motor Company, gives the 1996 MRS Fall Meeting/ICEM-96 plenary presentation on the globalization of science and technology.

time-dependent behavior of thin films.

Symposium $W$ emphasized modification or engineering of interfaces to improve overall material performance. The nature or structure of an interface affects the tendency of that boundary to undergo such processes as corrosion or fracture, but two new factors have renewed excitement: (1) development of new tools to measure large sets of interface characteristics; and (2) realization that materials can be processed so that the number of boundaries with good properties can be optimized.

Symposium $\mathrm{R}$ reflected the shared challenge to understand, control, and predict the structures and properties of inorganic solids. High-pressure synthesis resulted in refractory nitride glasses harder than $\mathrm{SiO}_{2}$ with high glass transition temperatures $\left(>800^{\circ} \mathrm{C}\right)$, and high refractive indices $(\sim 2)$. A new class of pnictide oxides, $\mathrm{Ln}_{3} \mathrm{Cu}_{4} \mathrm{P}_{4} \mathrm{O}_{2}$, exhibited interesting properties such as heavy-fermion and metallic behavior that, with appropriate doping, may lead to new superconductors. In the area of dielectric materials, mathematical examination of polarizability as a function of temperature made it possible to make reasonable numerical predictions of dielectric constants and their temperature dependencies.

The field of high-temperature ordered intermetallic alloys (Symposium Z) has matured to the point where processing and heat treatment innovations are supplanting alloy development approaches to improved properties. Recently, it was shown that the control of microstructure is more important than the control of alloy composition of TiAl alloys for property improvement.

Symposium T, Structure and Dynamics of Glasses and Glass Formers, covered inorganic compounds, metals, polymers, and biomolecules. An important driving force for the progress in this field is the MCT, which associates the characteristics of the glassy state with relaxation processes in the undercooled liquid, and quantifies these processes. Furthermore, significant improvements in scientific instrumentation to dynamically probe in the $\mathrm{GHz}$ to $\mathrm{THz}$ regime have been key to progress in this field. Another exciting development was the discovery of complex multicomponent alloys that can form bulk metallic glasses without requiring excessive cooling rates.

Smart systems (Symposium Y) constitute a special class of devices that can both sense a change in the environment and respond to that change in a useful way. Central to the operation of smart systems are materials that can serve as sensors and actuators: shape memory, piezoelectric, and magnetostrictive materials are examples discussed in this symposium. The presence of multiple phase transformations is a common thread found in all families of piezoelectric actuator materials. Manipulation of these transformations can be used to develop highly active ferroelectric actuator materials.

MEMS (Symposium I) are miniature

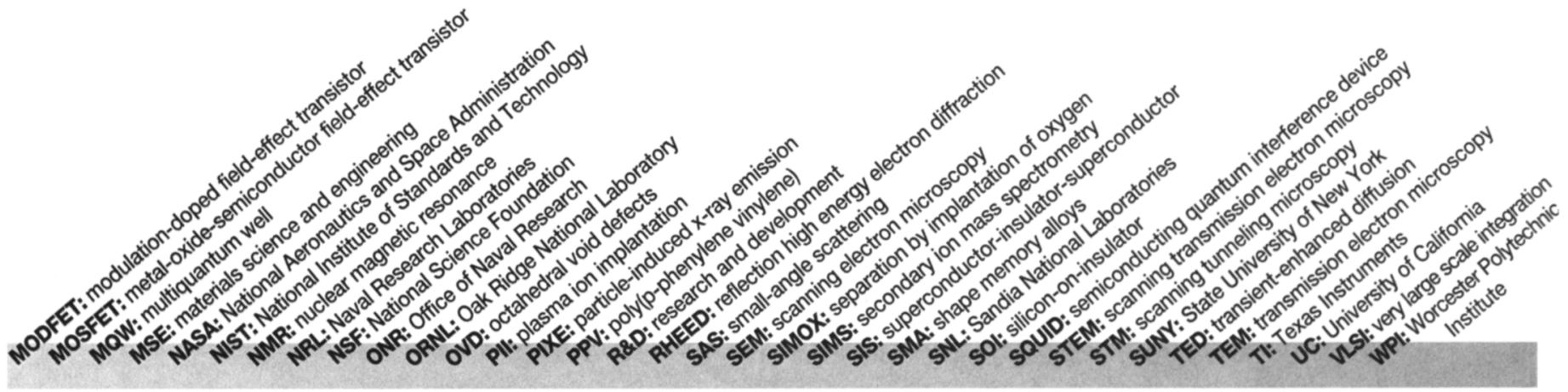


devices and systems manufactured using a variety of microfabrication techniques, including many originating from the IC industry. Once limited largely to physical sensors, the field of MEMS is broadening into a larger class of miniature systems which interact with their environment in many ways.

Catalytic materials are widely used in the oil, gas, petrochemical, and environmental industries, and are manufactured on scales of up to several hundred tons. Symposium $\mathrm{S}$ aimed to further develop the interface between progress in materials science and the field of catalysts. Mesoporous materials, in which the pores are in the $2-10 \mathrm{~nm}$ range, are currently of particular interest. Such materials may enable catalytic conversions of oil or chemical molecules which are too big to fit into microporous materials (pores up to $2 \mathrm{~nm}$ ), such as zeolites.

Symposium $U$ covered topics on the control of bulk and surface properties of biomaterials and biologically inspired materials. Various techniques of surface modification were utilized to control interaction between implantable devices and tissues; examples include plasmaenhanced CVD, chemical modification using self-assembled monolayers, ionbeam etching, and pulsed-laser deposition.

The concepts of statistical mechanics have long been among the most widely applied of physical ideas. The most notable aspect of Symposium EE, Statistical Mechanics in Physics and Biology, was the sheer range of subjects, including molecular biology, microbiology, chemical engineering, petroleum engineering, polymer science, and metallurgy, addressed by similar methods. Topics spanned from the behavior of DNA and how its intrinsic chirality causes it to curl up on itself to a new theoretical approach to the behavior of granular media presented by P.G. de Gennes allowing simple calculation of segregation and convection in such systems.

A focus of Symposium $\mathrm{HH}$, StructureProperty Relationships in Hardened Cement Paste and Composites, was microstructure's characterization, development, and relation to physical properties, such as diffusion of aggressive ions. The interfacial zone between cement paste and embedded materials has an important role in diffusion, and stress transfer across this zone influences mechanical properties. Cements are an important component of engineered barriers to the return of radioactive species to the biosphere and this topic was covered in a joint session with Symposium II on Scientific Basis for Nuclear Waste

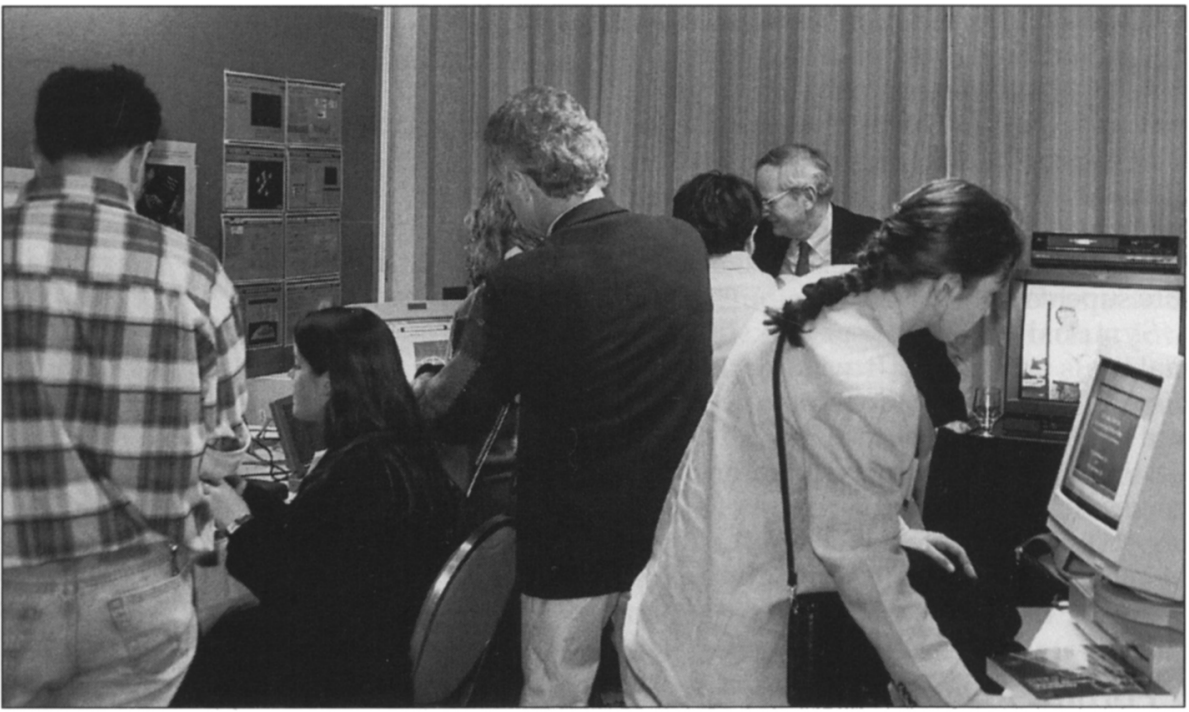

Attendees at the 1996 MRS Fall Meeting/ICEM-96 browse through software demonstrations of the Workshop on Materials Education (Symposium JJ).

\section{Management $X X$.}

Unique metallurgies of early European artillery and ancient medical instruments alike were examined in Symposium DD, Materials Issues in Art and Archaeology V. Analysis is key to understanding many ancient artifacts, and neutron activation analysis on Chinese porcelains, mid-IR spectroscopy to help identify museum plastics, ICP-MS on archaeomaterials, PIXE, and scanning Auger spectroscopy are among some of the techniques used. Other papers examined the technology of historical lead and silver production, bronze punic coins, metal nails, and a gold hoard from the late Roman/early Byzantine period, and artificial glasses and ceramics.

Symposium G highlighted recent applications of atomic-resolution imaging methods to surface and bulk defects, such as $Z$-contrast imaging, ARM (where applications of digital image processing have enabled the atomistic structure of internal interfaces to be determined with error limits as small as $0.01 \mathrm{~nm}$ ), and STM, which graphically demonstrated the capabilities of the technique for surface imaging and spectroscopic studies. STM also has a valuable role to play in interface characterization because it can uniquely access bandgap energies while providing structural information.

Symposium CC presented a wide range of problems in the areas of superconductivity, magnetism, complex systems, and kinetics. Complex systems benefit from combining $x$-ray and neutron scattering investigations. Inelastic $x$-ray scattering techniques to study kinetics of physical and chemical processes have come into play, with the study of collective excitations of liquid water being a first step toward the application of $x$-rays in the study of collective excitations in bulk matter, previously the exclusive domain of neutron spectroscopy.

During the last 10 years, a wide range of electrochemical processes have been developed for the synthesis of novel materials and structures. Investigators from different communities have come together for the first time at an MRS meeting (Symposium P) to present new opportunities and applications for electrochemical synthesis in materials science. The symposium focused on fundamentals of film growth, surface modification, synthesis, and deposition. New applications for electrochemical deposition include magnetic recording and MEMS devices.

Symposium GG was devoted to materials science issues in synthesis of cuprate superconductors. In thin-film studies, effort has increased to control structure at the atomic level, mostly using MBE, but also using sophisticated laser ablation systems equipped with in situ surface monitoring tools such as RHEED. Successful synthesis of the first high- $T_{c}$ SIS tunnel junctions was also reported. Several groups used atomic-layer engineering and epitaxial stabilization to fabricate new, metastable superconductor compounds. M. Lagües (ESPCI, Paris, France) announced successful synthesis 
of $\mathrm{Bi}_{2} \mathrm{Ca}_{2} 2 \mathrm{Cu}_{2} \mathrm{O}_{5}$ with $\mathrm{T}_{2}=53 \mathrm{~K}$. So far, all the known high- $\mathrm{T}_{\mathrm{c}}$ superconductors contained $\mathrm{CuO}_{2}$ planes. In contrast, this artificial new compound contains sheets which consists of $\mathrm{Cu}_{2} \mathrm{O}_{3}$ ladders. If this discovery is confirmed, this will be a new paradigm with a profound impact on theoretical understanding of high-temperature superconductivity.

Symposium JJ was a workshop on materials education. It was marked by discussions, presentations of new ideas, and real-time computer-based demonstrations. Instruction was given on techniques for addressing the range of learning styles needed for effective teaching.
Later in the session, the audience was guided through an exercise to self-discover how and why the photocopying process works. Instructional software is evolving toward that which achieves comprehensive, self-consistent, coherent sets of modules (akin to complete textbooks) in a finite time. A panel discussion on the graduate materials curricùlum raised several key questions for the education of MS and PhD candidates. An industrial perspective indicated that the current focus on near-term products, affordability versus performance, team orientation, globalization, and outsourcing require the graduate curriculum to

\section{Forum Solicits Input on NRC Study on Materials Physics}

A society-wide Forum sponsored by the Public Affairs Committee provided the status and encouraged feedback on a current study on the future of condensed matter and materials physics. This study is being undertaken under the auspices of the Solid State Sciences Committee of the Board on Physics and Astronomy within the National Academy of Sciences. It is part of a series of 10-year reassessments on the various branches of physics. A major objective of the forum was to let the materials research community know the current status of the panel study, which is midway through its work, and to provide an opportunity for feedback to the panel on those issues of particular concern to the materials community.

Venky Narayanamurti, chair of the panel, began the session by explaining the study's schedule and goals. Paul Peercy (Sematech) described the panel's first step, which was to frame the areas of coverage through a Condensed Matter and Materials Physics Workshop held last June. Julia Phillips (SNL) then described a research briefing document nearing completion, which illustrates, by narrative and technical sidebars, the impact of materials on modern life through a day-in-the-life of a small business executive. This first publication will serve to briefly communicate the excitement and impact of the field to largely nonscientific audiences and raise major issues facing the field. Frans Spaepen (Harvard Univ.) gave a synopsis of the current status of the Committee's deliberations, and Jim Roberto (ORNL) described the methods and types of community input being sought.

The Forum moderator, Tom Picraux (SNL), led an open discussion between the audience and panel which explored such issues as the handling of interdisciplinary studies, cross-cutting fields, facilities, prioritization, and how to best communicate the final report to science policymakers in order to ensure its effectiveness. For further information on this study or to provide input see the website at http:// www2.nas.edu/cmmp/.

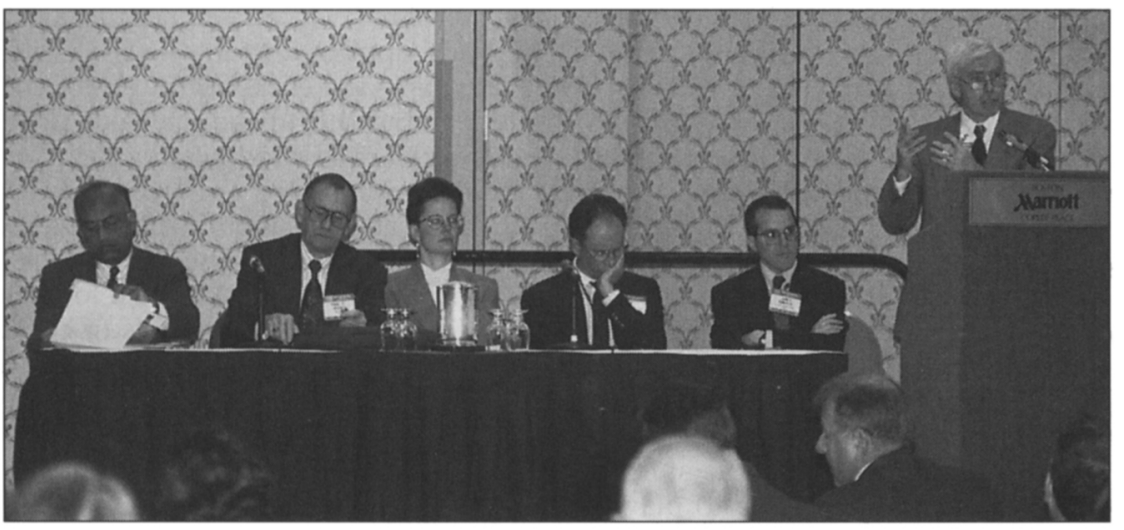

Panelists discuss the status of a study on the future of condensed matter and materials physics during a forum coordinated by the MRS Public Affairs Committee. (Left to right) Venky Narayanamurti, chair of the panel of the Solid State Sciences Committee of the Board on Physics and Astronomy within the National Academy of Sciences; Paul Peercy (Sematech); Julia Phillips (SNL); Frans Spaepen (Harvard University); James B. Roberto (ORNL); and Tom Picraux (moderator).

provide broad exposure to associated engineering disciplines, and research carried out in the context of multidisciplinary "real world" projects.

\section{Ion Beams Modify Electronic Materials and Hard Coatings}

(See MRS Proceedings Volume 438)

Researchers in Symposium A Materials Modification and Synthesis by Ion-Beam Processing, discussed materials science issues related to ion-beam modification and processing, in particular, electronic materials and hard coatings. In the electronic materials area, considerable attention remains on silicon technology where the shrinking device dimensions of microelectronic circuits are driving the need for ultrashallow implant depths. Joint sessions with Symposium B, Microstructure Evolution During Irradiation, examined critical microstructural issues pertaining to ion-beam processing of silicon such as TED and defect/damage behavior. The role of surface effects was debated and discussed for example in the presentation by $A$. Claverie (CEMES/CNRS) whose work on the thermal behavior of end-of-range defects indicated that the surface is not a strong defect sink. The emergence of PII as a major breakthrough for shallow implant, large-area processing was evidenced by successful hydrogenation and doping experiments in silicon reported in the symposium. The SIMOX and Smart Cut processes done by PII open new directions for SOI synthesis. In the area of interconnect materials, S. Mantl (Forschungszentrum Julich) presented a sophisticated analysis of electrical transport in ion-beam synthesized cobalt silicide wires. Using magnetoresistance measurements at low temperatures $(2-15 \mathrm{~K})$, weak localization effects were used to explain observed transport behavior.

Hard coating synthesis with ion beams is driven in part by demands for wear resistant recording media coatings. Nonequilibrium processes with ion beams were heavily discussed for the synthesis of novel metastable materials, such as carbon nitride, amorphous carbon (DLC), multilayers and nanophases. The scientific objectives of the work presented focused on providing an in-depth understanding of phase-formation and growth mechanisms of controversial metastable phases.

Symposium Support: ANL; High Voltage Engineering; Wacker Siltronic; Zentrum Mikroelectronik Dresden; Forschungszentrum Rossendorf; Danfysik A/S; Varian Ion Implant Syst.; Applied Materials, Implant Div.; FHR GmbH; Eaton Corp., Semiconductor Equipment Div.; and Diamond Semiconductor Group Inc. 


\section{Surfaces and Thin Films Have Extensive Reach}

(Ca: See MRS Proceedings Volume 440)

(Cb: See MRS Proceedings Volume 441)

Owing to the large number of abstracts submitted to Symposium $C$, the program was divided into two symposia, one emphasizing surfaces and the other concentrating on thin films. In Symposium $\mathrm{Ca}$, Structure and Evolution of Surfaces, experimental and theoretical studies of semiconductor, metal, ceramic, polymer, and self-assembled surfaces were presented. Most of the presentations could be classified into three broad categories: the structure and stability of surfaces, surface kinetic processes, and effects of surfaces and interfaces on physical and chemical properties. The mechanisms and evolution of roughness development and surface step structures received a great deal of discussion, as did the structure and kinetics of thin-film surfaces. A joint session with Symposium M, Control of Semiconductor Surfaces and Interfaces, provided several presentations concerning structural aspects of metal-semiconductor interfaces. Two special session topics that generated a great deal of interest were surface nucleation processes and the mechanics of surfaces and interfaces. The symposium also had the honor of having J. Tersoff (IBM-T.J. Watson) present his MRS Medal Award lecture on strain relaxation and its effect on the morphology of thin-film surfaces.

Symposium $\mathrm{Cb}$, Thin Films-Structure and Morphology, carried two major themes: kinetics and microstructural development during thin film deposition and the effect of stresses on thin-film growth and stability.

Areas to receive special emphasis included novel energetic growth processes, thin-film silicides and metallization, and the role of stresses in the time-dependent behavior of thin films.

Symposium Support: ORNL, LLNL, E.A. Fischione, and AEA Tech.

\section{Organic Materials and Fullerenes Conduct and Glow}

Highlights of Symposium D on Properties and Applications of Electronic Organic Materials and Fullerenes included talks on major advances in measurements of fluorescence spectral narrowing and superfluorescence of PPV by R. Friend (Cambridge Univ., UK) and derivatives of PPV and other $\pi$-conjugated polymers by A.J. Heeger (UC-Santa Barbara). Friend also described the electroluminescence of PPV-based LEDs under intense pulsed carrier injection, which did not exhibit spectral narrowing.

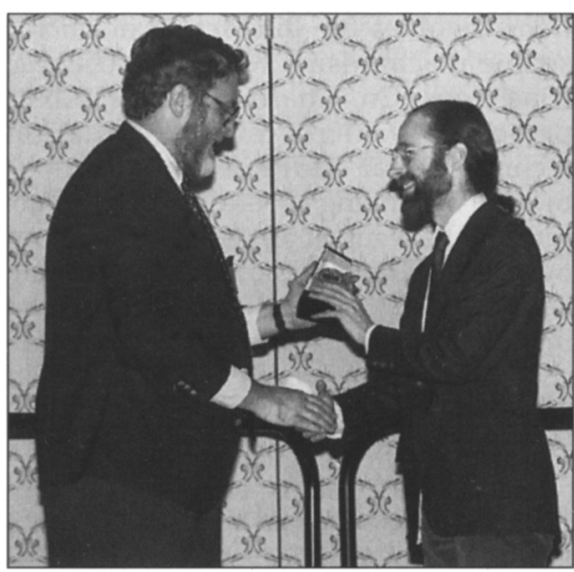

Jerry Tersoff of IBM T.J. Watson Research Center (right) receives the 1996 MRS Medal from MRS President Carl V. Thompson (left)

In a related talk, K. Pichler (Cambridge Display Technologies, UK) described recent advances in prolonging the lifetime of PPV-based LEDs to $\sim 1200 \mathrm{~h}$ at initial and final luminous outputs of 100 and $50 \mathrm{Cdgm}^{2}$, respectively, and in developing the manufacturing technology required for future commercial products which will be based on polymer LEDs.

The synthesis of novel materials was reported by T. Swager (MIT) who showed how combinations of conducting polymers and crown ethers could lead to molecular recognition events which dramatically altered conductivities. E.W. Meijer (Eindhoven Univ. of Tech.) showed how chiroptical properties of conjugated polymers could be harnessed to control aggregation in solution. He also illustrated how molecular self-assembly could lead to ordered ladderlike polymers held together by hydrogen bonds. A.B. Smith (Univ. of Pennsylvania) highlighted the exquisite control of properties of novel fullerene epoxides and related compounds.

Other highlights included experiments on single nanotubes and single-wall nanotubes by researchers who also used ATM to study their mechanical properties. A. Thess et al. (Rice Univ.) showed the intrinsically metallic character of the tubes: The tunneling experiments reported by D.L. Carroll et al. (Max-PlanckInst., Stuttgart) demonstrated the power of STM by showing the local density of states in the nanoscale range. P.C. Eklund (Univ. of Kentucky) showed impressively how Raman spectroscopy can be used to analyze size distributions of single-wall nanotubes.

Symposium Support: Digital, ICI Acrylics, and TI.

\section{Defects Examined in Si and Other} Electronic Materials

(See MRS Proceedings Volume 442)

Symposium E provided a vivid picture of the current problems, progress, and methods in Defects in Electronic Materials. Most of the highlights can be described within two themes: new techniques in defect-studies and current problems in $\mathrm{Si}$ and the processing of materials into devices.

The aspect on new techniques began with the tutorial which explored the effects of decreasing size and increasing strain on the effectiveness of magnetic resonance and optical spectroscopy to analyze defects. G. Dollinger (Munich) discussed an ion-beam method for quantitative depth profiling of light impurities which may prove useful in developing standards for SIMS. K. Takeda (Hitachi) described a two-beam optical method for detecting microdefects near the surface or Si wafers. Due to its high measurementthroughput, this method could replace current methods employed in productions. P.G. Ebert (Julich) presented work describing the compensation of donors in GaAs from STM pictures from cleaved surfaces. The micrographs resolve $\mathrm{Si}$ donors, $\mathrm{Si}$ acceptors, Si-pairs and clusters, and $\mathrm{Ga}$-vacancies and $\mathrm{Si}$-vacancy pairs.

Many speakers addressed defects related to Si-based systems and defects encountered in processing. A. Maiti (ORNL and Vanderbilt) presented theory and experiment showing cooperative chemical rebonding of impurities in $\mathrm{Si}$-grain boundaries. D. Auret (Univ. of Pretoria) gave an overview of the plasma-induced defects in GaAs. The electronic properties of these defects were assessed with DLTS and $I-V$ studies. M. Itsumi (NTT) introduced OVDs important to VLSI technology. In a following talk, M. Kato (Shin-Etsu Handotai) used TEM to show the growth of the OVDs, their oxidation and further growth.

Symposium Support: Bruker Instr., IEOL USA, Nippon Steel, SEH American, Shin-Etsu Handotai, Sumitomo SiTiX, Temic Mikroelectronik, Wacker Siltronic, Oxford Instr., Bunkoh-Keiki, and ONR.

\section{Numerical Simulations Model Microstructured Evolution}

The papers comprising Symposium F, Microstructural Evolution in Bulk Phases, covered a variety of phase transformation and microstructure topics, ranging from nucleation to grain growth and coarsening to solidification. A common theme is the increasing use of numerical simulations to better understand and predict the development of microstructure in various material processes. 
One of the newer methods of modeling the evolution of microstructure is the phase-field method, which describes the evolution of a single field variable that has a constant value within each phase and varies sharply in a narrow region between phases. Applying the phase-field method involves numerical solution of a single field equation, and eliminates the need to explicitly track the location of a sharp interface. The phase-field method has been applied to grain growth phenomena by D. Fan et al. (LANL), who found that the boundary motion exhibits classical behavior if at least seven grid points are located within the boundary width. M.K. Venkitachalam et al. (Pennsylvania State Univ.) developed free energy equations that allow the phase-field method to address anisotropy effects during grain growth. Another issue in numerical studies of phase transforma- tions involves the interaction of microscopic mechanisms with macroscopic conditions. Ch. Charbon et al. (LANL) presented a micro/macro simulation technique that addresses the development of impinging spherulitic microstructures. H.P. Wang et al. (GE) presented an overview of how micro/macro modeling is used to tailor process conditions, allowing the development of high-performance components for turbine engines and related products for which material reliability is critical.

\section{Atomic Level Viewed by Direct Imaging}

The last several years have witnessed a considerable expansion in the breadth and depth of studies involving STM and HREM. Symposium G, Atomic Resolution Microscopy of Surfaces and Interfaces, highlighted recent applications of atomic-

\section{Heading Toward the Lab or Leaving it for Alternative Careers}

Several career-related events took place during the 1996 MRS Fall Meeting/ICEM-96.

Nontraditional Careers for Materials Scientists and Engineers, a breakfast panel session cosponsored by the Materials Research Society Membership Committee and Women in Materials Science and Engineering (WIMSE), was held one morning. Seventy people started their day at 7:00 a.m. to hear about unusual and exciting career opportunities for materials scientists and engineers.

The speakers included Ana Rodriguez, management consultant at Coopers and Lybrand; Rick Neifeld, a patent lawyer at Oblon, Spivak, McClelland, Maier \& Neustadt, P.C.; Kelly Kirkpatrick, the 1995-1996 Materials Research Society/Optical Society of America Congressional Fellow; and Betsy Fleischer, editor of MRS Bulletin. They shared their professional evolution toward their chosen careers, as well as advice for those considering a career change and for university advisors who needed help for their students who were considering nontraditional career options.

In making their career decisions, all panelists recognized that throughout their graduate and/or postdoctoral careers, they had other strong interests: Fleischer had always been involved with school or local publications, and Rodriguez participated in technical consulting work on the side. All of the panelists found that making the transition was facilitated by the support and encouragement of their colleagues and advisors. The faculty advisor's understanding and recognition that the nontraditional career choice was not a "step down" from pursuing an academic or industrial research career, but rather a way for the students to incorporate all of their interests into their job was extremely important.

Several members of the audience questioned how the panelists found their current positions. Two of the panelists cited the mass media and Congressional science and engineering fellowship programs (MRS cosponsors a Congressional fellow each year) overseen by the American Association for the Advancement of Science (AAAS) as excellent ways to explore other career opportunities. Neifeld said that seeking employment at the U.S. Patent and Trademark Office would be a good way to explore patent law prior to committing to law school. Science's NextWave highlights many types of science careers on the AAAS website at http://www.aaas.org./

A career workshop and networking session helped job seekers looking for more traditional career opportunities. The networking session was organized by Michal Freedhoff, chair of the Employment Subcommittee. This innovative idea was to provide students and early career researchers an opportunity to develop a network with people active in MRS or at institutions of interest to them. Those taking part included graduate students and postdocs wanting to learn the ropes on career tracks or MRS involvement. The session was set up with tables designated by "government labs," "academia," "industry," and the like, inviting students to come by for a chat. The conversations revolved around resume writing, citizenship issues, and who-knows-who, the last being truly in the spirit of expanding one's network. "I found that my own network grew during the process, and during the meeting week I continually ran into folks I met during the session," said Al Hurd (SNL), one of the mentors. The networking resonated well for the 125 or so attendees. Another networking event is scheduled for the 1997 MRS Spring Meeting in San Francisco. resolution imaging methods to surface and bulk defects. S. Pennycook (ORNL) opened the symposium with a set of stunning examples of Z-contrast imaging utilizing a $300 \mathrm{keV}$ STEM, in particular demonstrating the advantage in terms of enhanced atomic column visibility accruing from maximum entropy image restoration. F. Ernst (MaxPlanck-Institut, Stuttgart) showed equally remarkable examples recorded with the Stuttgart $1250 \mathrm{keV}$ ARM where applications of digital image processing have enabled the atomistic structure of internal interfaces to be determined with error limits as small as $0.01 \mathrm{~nm}$. M. Mills (Ohio State Univ.) used atomic-resolution imaging of interfaces in intermetallics alloys to provide crucial insights into macroscopic mechanical behavior, while $\mathrm{C}$. Hetherington (LBL) described atomistic studies of interfaces in mazed Au bicrystals.

Several leading experts in the field of STM provided overviews that graphically demonstrated the capabilities of the technique for surface imaging and spectroscopic studies. E. Williams (Univ. of Maryland) concentrated much of her attention on current-induced mass transport across stepped $\mathrm{Si}$ surfaces as a function of temperature, while J. Weaver (Univ. of Minnesota) reported on the various mechanisms whereby bromine contributes to the surface etching of $\mathrm{GaAs}$ surfaces. L. Whitman (NRL) reviewed recent atomistic studies of high-index Si and III-Sb (001) surfaces, in the latter case showing that stress has a crucial role in influencing the reconstructed surface stability. R. Feenstra (CMU) reported cross-sectional studies of III-V compound semiconductor interfaces which demonstrated that the STM also has a valuable role to play in interface characterization because it can uniquely access bandgap energies and band offsets as well as provide structural information. L. Marks (Northwestern Univ.) demonstrated that the plan-view imaging geometry in the electron microscope was competitive with the STM in terms of yielding atomic-level information about reconstructed- and doped-Si surfaces.

Symposium Support: JEOL USA, Digital, Park Scientific, Philips Electronic, and TopoMetrix.

\section{Case Closed on Low-Dielectric Constant Materials?}

The important matter of Low-Dielectric Constant Materials, Symposium $\mathrm{H}$, was covered during four sessions and a subsequent tutorial. Questions that arose indicated that the touched topics are vital to the future of microelectronics. Among the vast number of possible candidates to be used as low-dielectric constant materials, only a few could be highlighted: organic 
layers like parylenes, polyimides, or $\mathrm{BCB}$ deposited by spin-on, or CVD aerogels, or xerogels, amorphous carbon FSG.

The lowest dielectric constants reported so far are those of the organic materials $(<2.5)$ and those of the air encapsulating materials $(<2)$ which make these layers the most promising candidates. The decision as to which material will be used is not made, yet. BEOL process temperatures up to $450^{\circ} \mathrm{C}$ dictate the thermal stability requirements of intermetal dielec- trics, largely eliminating the majority of organic polymers from consideration. For this reason it is important to closely combine expertise in chemistry, tool engineering, thin-film characterization and process integration in a semiconductor fabrication

\section{Von Hippel, Turnbull, MRS Medal, and Graduate Student Awards Presented}

On Wednesday, the Von Hippel, Turnbull, MRS Medal, Graduate Student Awards, and a recognition award (uncommonly presented) to Eric S. Hellman (AT\&T Bell Labs.) for spearheading the production of the MRS Internet Journal of Nitride Semiconductor Research were presented during the MRS Awards Ceremony. Articles based on the award lectures are scheduled to appear in future issues of MRS Bulletin.

Immediately after the award ceremony, Von Hippel award recipient Sir Alan H. Cottrell of Cambridge University covered "The Art of Simplification in Materials Science" in an elegant presentation on ways to take complicated scientific principles down to the bare essentials through approximations, just as a cartoonist portrays famous figures with a few simple carefully placed lines. For instance, the free electron theory of metals assumes each conduction electron moves as if free from electrical interactions, despite the immensely strong electrical fields exerted on it from the nearby atoms and other conduction electrons. Yet this simplified model was successful in explaining various properties of metals.

Robert Newnham, Alcoa Professor of Solid State Science at The Pennsylvania State University received the David Turnbull Lectureship and presented a lecture on "Molecular Mechanisms in Smart Materials." He defined smart, very smart, and intelligent materials. Smart materials carry out two of the functions of a living system-sensing the surroundings and responding to that sensed signal. To go from a smart to a very smart material, one moves from linear couplings to higher order effects. "And finally way down the line," Newnham mused, "we're going to make materials that make the right moral decisions." Smart ideas for the future could include systems to help the human body deliver insulin, windows that automatically control the flow of energy into a house, and tennis rackets with self-adjusting overhead smashes. Atomic mechanisms of smart materials for piezoelectrics, electrostrictors, magnetostrictors, and shape memory alloys that he described involve two transformations to help tune properties. Composites likewise rely on coupled phase transformations of the various components.

MRS Medal Award recipient Jerry Tersoff, IBM T.J. Watson Research Center, presented a talk on strain relaxation and roughening of thin films. These strained layers form the basis for devices such as quantum-well lasers and heterojunction bipolar transistors. Strain tunes bandgaps, and in indirect gap materials this strain even increases the mobility of the electrons.

There are two competing modes of relaxation seen in these strained systems. One is direct nucleation of dislocations in the planer film and the other is strain roughening. Tersoff described a way of understanding the roughening in the case where the film is strictly faceted. He explained that any strained layer is actually unstable and any small perturbation away from a perfectly flat surface will grow exponentially with time so that spontaneous roughening of the surface will occur. At lower temperature, where the surface is faceted and the strain layer is metastable, the surface can lower its energy by roughening but there is an energy barrier to do so. If that energy barrier is much larger than the thermal energy, the roughening can effectively be suppressed on any relevant time scale, he said. In the case of high misfit, the surface roughens essentially mmediately. Once it is roughened there is a low barrier for dislocations; so once the layer is thick enough that it is energetically favorable to introduce dislocations, dislocations form. On the other hand, at lower misfit, the surface remains smooth at all times and with a high barrier for introducing the dislocations which means that once a dislocation is introduced, it is much easier for that dislocation to grow than it is to introduce a second dislocation. Long misfit dislocations form and therefore a much lower density of threading dislocations forms implicating that this is the regime needed for applications. Surface roughness, he explained, can be suppressed by lowering misfit, compositionally grading the strained area, using surfactants that increase surface energy and anisotropy, and lowering the temperature, with each method acting to control the energy barrier for the nucleation of the faceted islands or pits.

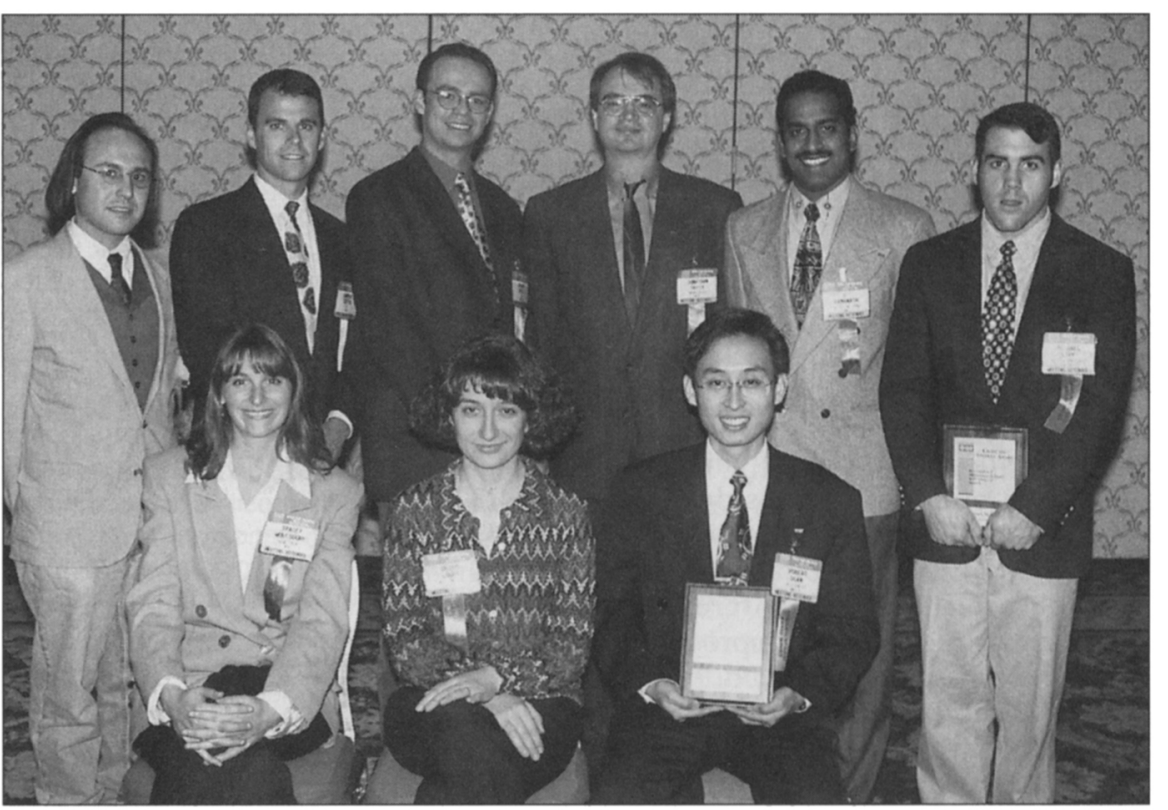

Nine Graduate Student Awards were presented at the 1996 MRS Fall Meeting/ICEM96 in Boston. The awards are intended to honor and encourage graduate students whose academic achievements and current materials research display a high order of excellence and distinction. Each award consists of a $\$ 250$ cash prize, payment of the registration fee for the meeting, and a presentation plaque.

(Graduate Student Award Recipients seated left to right) Tracey Wolfsdorf, Despina Louca, and Robert G. Duan.

(Standing left to right) Jonah Erlebacher, Darren T. Castro, Jochen Betz, Jonathan E. Guyer, G. Ramanath, and Michael M. Lipp. 
environment. The time frame over which low-dielectric constant layers will be introduced into volume production of ICs can only be estimated. The overall feeling was that FSG will probably survive only one device generation.

\section{MEMS Applications Broaden Beyond Physical Sensors \\ (See MRS Proceedings Volume 444)}

Researchers in Symposium I, Materials for Mechanical and Optical Microsystems, reported on worldwide developments in the materials aspects of MEMS, which are miniature devices and systems manufactured using a variety of microfabrication techniques, including many originating from the IC industry. A key feature of MEMS is that the mechanical properties of the materials, in addition to their electrical behavior, are important in determining system performance. Once limited largely to physical sensors, the field of MEMS is broadening into a larger class of miniature systems which interact with their environment in many ways.

Many of the papers were devoted to characterization and testing of MEMS materials. Several invited speakers provided broad overviews of microsystem technology. Among these, talks by S. Johansson (Univ. of Uppsala) on technologies for assembling parts and by E. Obermeier (Technische Univ. Berlin) on testing and characterization, were especially well received.

The tutorial given by H.V. Jansen, M. de Boer, and J.G.E. Gardeniers of the University of Twente, Netherlands, concentrated on anisotropic reactive ion etching of silicon, especially a method involving "black silicon" which was developed by the instructors at Twente. In this method, the deposition of polymer byproducts on microstructure sidewalls during the etching process is carefully controlled and exploited to fabricate tailored etch profiles. Many interesting types of microstructures can be produced with this process, as evidenced by the many SEM photographs shown in the tutorial. Of particular interest in the MEMS area are the high aspect ratio structures which are difficult to make in a reproducible fashion.

\section{Broad Range of Topics Covered on Electronic Packaging \\ (See MRS Proceedings Volume 445)}

Symposium J on Electronic Packaging Materials Science IX provided three days of diverse, leading-edge research including sessions on flip chip and solder technology, future packaging technology, manufacturing technology in packaging, packaging materials and metrology, interfacial adhesion and fracture, and packaging reliability and testing. The impressive breadth of topics included fundamental and theoretical atomic scale science, experimental correlations, and design verification of semiconductor packages.

Symposium Support: TI and INTEL.

\section{Progress in Ultrathin Insulating Films Primarily Industry-Driven}

(See MRS Proceedings Volume 446)

The technical program for Symposium K, Amorphous and Crystalline Insulating Thin Films, was divided into the following sessions: thin $\mathrm{SiO}_{2}$-based dielectrics, silicon oxynitride, low-dielectric constant and organic dielectrics, high-dielectric constant

\section{Tenure: Love It or Hate It}

The Academic Affairs and Membership Committees of the Materials Research Society sponsored the MRS Junior Faculty Forum, "Tenure: Why We Love It/ Why We Hate It," on Sunday. To cover the scope of materials academia, the panel included Diran Apelian from WPI, a primarily undergraduate institution; Reza Abbaschian from the University of Florida, a state university; and Thomas Eagar from MIT, a research institution. Daryush Ila from Alabama A\&M was invited to moderate the discussions.

The purpose of the forum was to encourage discussion on the pros and cons of the tenure process which is currently under acute scrutiny in the United States. As universities face downsizing and society demands changes in curriculum, tenure is often seen as an impediment to flexibility. Some academics feel that changes in the tenure process must be made, while others feel that to change it at all is to abolish it. Several universities turn to post-tenure reviews to solve the potential hazards of the tenure process.

Eagar commented that the tenure process at MIT has changed over the past two decades. Junior faculty review meetings with the department head have increased in frequency from a few meetings over several years to twice per year with mentoring from a career development committee. Since Eagar has been department head, his department has instituted twice annual reviews for all faculty in which the previous year's progress and the following year's goals are discussed. Eagar views tenure as a two-way contract in which an individual agrees to abide by the code and standards of the profession in exchange for a degree of autonomy in pursuing one's professional career similar to partners in law firms and medical practices. When the contract is broken, department heads are responsible to use whatever "carrot" or "stick" they have to correct the situation. Each time the organization makes a tenure decision, it is either reaffirming or resetting the standards of the organization.

Abbaschian defined three important criteria of the academic profession: teaching, research, and service. At the University of Florida, only excellence in the first two are evaluated for tenure. Annual reviews by the department chair determines whether a candidate is progressing toward tenure. In this process, weak areas are identified early so improvement can be made. He agrees with Eagar that tenure is not a guarantee for lifetime employment, but is rather a contract. However, he noted that department chairs at state schools are not as free to use a "stick" as private schools due to faculty unions. In many state schools, engineering faculty members are subject to union rules even when they would prefer not to be part of a union.

Apelian identified the negatives of the tenure system as infrequent cases in which standards are abused by a tenured faculty, the establishment of "departmental loyalties" rather than university views, and fiduciary responsibilities of Board of Regents in case of financial crisis. However, the positive aspects include the building of equity into the academic system and the setting of standards, which are controlled by measuring them through evaluation using definitions that junior faculty members should retrieve from the faculty handbook and discussions with their department chair.

An interesting contrast between the types of institutions was revealed by the question of five-year contracts versus tenure. Apelian said five-year contracts are being considered but that post-tenure reviews are currently effective in maintaining standards. Eagar personally advocated five-year contracts due to abuse of the tenure system. Abbaschian viewed tenure as a means of protecting faculty from state budget cuts and other nonacademic-related matters, stating that without tenure, refusals to renew may happen based on the budgetary situation when a faculty member's contract is up rather than on that person's work.

Funding was viewed as an indirect influence in the tenure process. Without funding, the number of graduate students decline and, therefore, faculty members' publication record may decline. Impact was stated to be more important than the number of contracts that are received, and yet the panel urged young faculty to negotiate for start-up funds when entering a department. Collaborations with other departments and industry was encouraged, especially for faculty in schools with limited facilities. Apelian especially encouraged these faculty members to find an industry and discern their needs, rather than write proposals based solely from their own expertise.

The next MRS Faculty Forum will be held at the 1997 MRS Spring Meeting in San Francisco and the topic will be Grantsmanship. 
materials, $\mathrm{SiO}_{2}$ growth and properties, and SOI materials. The session on ultrathin oxides dealt with topics ranging from the effects of the enhanced performance of deuterated oxides, the fabrication of hydrogen-free oxides, the effects of differing gate electrodes to the effects of postmetallization annealing of these dielectrics. Apparently, much of what was learned on thicker $\mathrm{SiO}_{2}$ films may not necessarily be transferable to the ultrathin regime $(<5 \mathrm{~nm})$.

Although thermal $\mathrm{SiO}_{2}$ has been the dominant dielectric for thin films in microelectronic applications, an immense need is apparent for low-dielectric constant materials for interlevel dielectrics (less capacitive cross-talk and reduced delay) and high-dielectric constant materials to minimize the space and maximize the capacitance of storage devices such as DRAMs. The sessions devoted to these topics showed that materials such as $\mathrm{Ta}_{2} \mathrm{O}_{5},(\mathrm{Sr}, \mathrm{Ba}) \mathrm{TiO}_{3}, \mathrm{~Pb}(\mathrm{Zr}, \mathrm{Ti}) \mathrm{O}_{3}$, and $\mathrm{SrBi}_{2} \mathrm{Ta}_{2} \mathrm{O}_{9}$ dielectrics are maturing at a rapid rate. Some of the largest breakthroughs have been in processing integration of these complex oxides into standard Si CMOS processing lines as well as the improved reliability of these materials largely due to electrode technology and materials growth. The development in this field has been primarily industry-driven.

Two sessions dealt with the structure, characterization, and devices built from SOI materials formed by either the Smart Cut Unibonds $\left.^{(}\right)$process or by $\mathrm{O}^{+}$implantation into Si substrates (SIMOX process). These techniques have come to fruition as viable methods for producing commercial devices that require radiation hardness and hightemperature or high-speed operation. Oxygen vacancies still appear to be a thorn in the flesh in terms of buried oxide reliability. Nonetheless, due to these defects, SOI materials may have some unique properties and applications. The vacancies have been proposed to act as cracking sites for $\mathrm{H}_{2}$ to form mobile protons $\left(\mathrm{H}^{+}\right)$which can be reliably and controllably moved throughout the buried oxide (BOX). Such mobile charge can be used to change the channel conductivity in MOSFETs and thus form the basis of novel nonvolatile memory devices.

The symposium introduced a wellattended tutorial on SOI materials analysis device operation and characterization techniques.

Symposium Support: NEC Corp., SOITEC USA, and Hitachi.

\section{Semiconductor Surfaces Controlled through Passivation and Self-Assembly (See MRS Proceedings Volume 448)}

Symposium M on Control of Semiconductor Surfaces and Interfaces represented

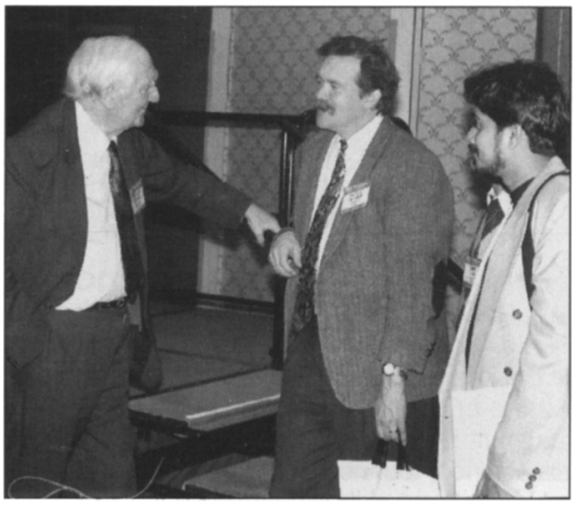

was presented, showing that similar silicide phases were formed as with $\mathrm{Si}$, but they generally occurred at higher temperatures. Ge clustering was also reported in these studies.

Symposium Support: ONR.

\section{Violet CW Room-Temperature Laser Diode Demonstrates Continued III-V Nitride Progress}

(See MRS Proceedings Volume 449)

Symposium N on III-V nitrides addressed both theoretical and experimental progress in this rapidly developing field. It covered issues related to crystal growth and structure, optoelectronic characterization, theoretical modeling, and device processing and characterization.

S. Nakamura (Nichia) opened the sesCon Hippel Award recipient Sir Alan mingles with attendees after his lecture on "The Art of Simplification in Materials Science" at the 1996 MRS Fall Meeting/ICEM-96.

research in four broad areas: surface passivation and modification by etching, controlled growth (including self-assembly of quantum dots and lines), properties of metal/semiconductor interfaces, and in situ and $e x$ situ characterization techniques.

In the surface passivation area, various sulfur-based passivation treatments were examined for the III- $\mathrm{V}$ system-including the use of low-temperature GaAs-and $\mathrm{Cl}$ etching and resultant damage were addressed in the silicon processing section. In the controlled growth area, the issues included surfactant mediated epitaxy and suppression of Ge segregation in the $\mathrm{SiGe}$ system, growth on $\mathrm{H}$ terminated surfaces, and examination of the resultant interfaces, especially in terms of changes in the growth mode and roughening. In terms of self-assembly, the formation of strained quantum dots on various semiconductor surfaces was reported. The effects of strain at the dot/substrate interface on the island size and distribution were examined, as well as the kinetics of atom incorporation into the existing strained dots. The effects of strain relaxation on the size and distribution of these structures were also addressed. Results indicated that the size and size distribution of these structures increased dramatically once strain relaxation occurred.

The interactions of various metals with semiconductor surfaces were also examined from a structural as well as electrical perspective. The deposition of metals such as $\mathrm{Ga}, \mathrm{Al}, \mathrm{Te}$, and $\mathrm{Pb}$ on facet surfaces was reported, and in some cases, metal lines could be formed by a proper choice of metal and facet surface. The initial silicide formation on $\mathrm{SiGe}$ and $\mathrm{SiGeC}$ sion, announcing the fabrication of InGaN multiquantum-well violet laser diode capable of $\mathrm{cw}$ operation at room temperature with $35 \mathrm{~h}$ lifetime. A number of other researchers in the lasing session discussed the mechanisms of lasing and the physics of optical gain and stimulated emission in this class of materials.

Progress has been reported on bulk GaN and AlN growth. S. Porowski (Polish Academy of Science) reported the growth with dimensions of about $1 \mathrm{~cm}^{2}$ and dislocation density of $10^{3}-10^{5} \mathrm{~cm}^{-2}$. S. Sakai (Tokushima Univ.) and C. Balkas (N. Carolina State Univ.) reported on their work in growing GaN and AlN by sublimation methods.

Progress in MOCVD growth of these materials was reported by a number of researchers. P. Kung (Northwestern Univ.) reported the growth of $\mathrm{GaN}$ on sapphire with dislocation density less than $10^{7} \mathrm{~cm}^{-2}$. Growth by MBE focused on the development of InGaN/AlGaN multiquantum-wells. High-quality InGaN MQWs were reported by $\mathrm{H}$. Riechert (Siemens), R. Singh (Boston Univ.), and M. Johnson (N. Carolina State Univ.).

The growth and characterization of InGaN and AlGaN alloys were discussed in a number of papers. Theoretical arguments for phase separation in InGaN alloys were presented by G. Springfellow (Univ. of Utah). Evidence for ordering in AlGaN alloys was presented by $D$. Korakakis (Boston Univ.).

S. Yoshida (Electrotechnical Lab Japan) reported progress on the growth of cubic GaN. Other researchers addressed issues related to the study of inhomogeneities (F. Ponce, Xerox) or second phases (M. Stutzman, Walter-Schottky Inst.). The role of strain was addressed by B. Gil (Univ. of Montpellier).

The theory of point defects was of GaN single crystals at high pressure 
addressed by C. Van de Walle (Xerox) and V. Fiorentini (Univ. of Gagliari), who reported that $\mathrm{Be}$ is the most promising $p$-type dopant for GaN. K. Smith (Boston Univ.) reported surface electronic structure in $\mathrm{GaN}$ using angle-resolved photoemission.

Progress in device processing has been reported by J. Zolper (SNL), R. Shul

\section{IUMRS Forum Explores Int'I Cooperation in Materials Science}

The IUMRS International Forum on Materials Research and Education Policy held December 1 was organized by R.P.H. Chang (Northwestern Univ.) and sponsored by the International Union of Materials Research Societies. The panelists discussed policies and plans on the future of research and education that are of mutual interest in the global community. The forum was designed to foster international dialogue and collaboration among scientists and governments in the area of materials science, technology, and education, with a particular interest in how the development of advanced materials can improve living standards while conserving natural resources and protecting the environment. Seven invited speakers from three continents gave reports from their respective countries or regions.

Marye Anne Fox, the keynote speaker from the University of Texas, spoke on the reshaping of graduate and undergraduate education in materials science and engineering in the United States. She emphasized the importance of interdisciplinarity in education, the need for research universities to address problems of societal importance, the need to reduce the gap between research and product development, the need to provide alternative career paths for graduates in research, and the shortage of educated labor force.

Lorenzo Gomez of Instituto de Fisica, Mexico spoke on the new national materials initiatives to fund research and education. Mexico is also a partner in the Pan-American cooperation in materials research and education effort.

Kotobu Nagai of the Science and Technology Agency of Japan spoke on research and technology for advanced materials in Japan. Since 1995 a Science and Technology Basic Law came into force in Japan. The background of the Basic Law is that Japan, as an advanced industrial nation, must make greater qualitative contributions to society through science and technology. Under this law, systematic reforms must take place. The most important issue is to obtain and cultivate quality human resources that will support the future. Equally important is the need to increase the government expenditure on research and development to the same ratio of GDP as the United States and Europe by the year 2000. In addition to international cooperation, Nagai's agency is launching a 10-year project on structural materials for the 21 st century.

Lih J. Chen of The National Tsing Hua University reported on the progress of materials R\&D and education in Taiwan over the past 20 years. With the support of the government, advice from foreign materials scientists, and a large number of U.S.-educated faculty members on university campuses, Taiwan has become one of the leading producers in information products. The Materials Research Laboratory (in the industrial city of Hsinchu) with an annual budget of $\$ 50$ million/year has played an important role in transferring technology to high-tech industries there.

Jean Pierre Massue of the Council of Europe spoke on the "Multimedia Optimization and Demonstration for Education in Microelectronics." This is a new EU Telematics Applications Programme with partners from universities and industries throughout Europe. The purpose and goal of this program are to provide education and continual education to potential workers and current workers in the field of microelectronics. The program will make use of the latest information and communications technology such as video links and CD-ROMs for both on-site and distant learning and training.

Heng-De Li of Tsinghua University spoke on the general guidelines of the Chinese government policy to build the country through science and education by adopting a market system and regional economical developments. In addition, special emphasis will be placed on accelerating the progress of science and technology in agriculture, high-tech products, infrastructure, and societal benefits. Plans are under way to double the science and technology budget.

Rustum Roy of The Pennsylvania State University spoke on "New Directions in Materials Education and Service." He presented a critique of the present directions in the materials field, attributing it to a fundamental error in epistemology. Roy referred to the analysis by major historians that the vector of discovery is from human interest to technology to science, rarely if ever along the linear model of basic science to applied science to technology. He made the case for the central and key importance of "materials" in human history (stone age to bronze age to silicon age) and in science and in contemporary research. He accused the MSE community of great pusillanimity in not seizing the central position among the sciences from the "PCB" (physics, chemistry, biology) establishment. The MSE community, he argued, should clearly be at the focal point of $\mathrm{K}-12$ education in science, and the interpretation of science to the public through real (i.e., material) achievements and not virtual achievements such as "life on Mars." Finally, within MSE research he foresaw imminent changes to applications-driven science (already a fact in U.S. industry to expand slowly into government), driven not by promises of super performance but by existing "technology traction," and having as its goals "cheaper, faster, or greener" manufacturing.
(SNL), and S. Pearton (Univ. of Florida). These groups are developing ion implantation, etching, and thermal annealing methods. Progress in electronic devices was reported by S. DenBaars (UC-Santa Barbara) and S. Binari (NRL). MODFET structures with high transconductance and very high gate to drain breakdown were reported.

Symposium Support: ONR, Xerox-PARC, Morton Intl, IEOL USA, AIXTRON, Rockwell Intl, Fujitsu, Matsushita Electric Industrial Co., AIXTRON Semiconductor Tech. GMBH, and SONY.

\section{Semiconductors Developed for Infrared Applications}

(See MRS Proceedings Volume 450)

Symposium O, Infrared Applications of Semiconductors-Materials, Processing and Devices, focused on the IR applications of semiconductors and superlattices. Long wavelength detectors and sources as well as nonlinear applications attracted the most attention in this symposium. Researchers involved in developing diode lasers for wavelengths larger than $3 \mu \mathrm{m}$ reported their latest results during the first two sessions. Invited speakers presented state-of-the-art results on the antimoniderelated structures such as InAsSb/ InAlAsSb (type I superlattices) and InAs/InGaSb (type II superlattices). Results were reported for IR lasers grown on InAs substrate with wavelength ranging between 3.2 and $3.5 \mu \mathrm{m}$ that have operated pulsed up to $225 \mathrm{~K}$. On the other hand, lasers grown on $\mathrm{GaSb}$ substrate have operated pulsed up to $165 \mathrm{~K}$ and $\mathrm{cw}$ to $128 \mathrm{~K}$. Other significant results on the antimonide-related quantum-wells and superlattices were reported by both invited and contributed speakers. Sources and detectors based on GaAs-related quantum-wells were the subject of several invited and contributed papers. Other materials such as $\mathrm{HgCdTe}$ and $\mathrm{ZnGeP}$ were the subject of two large sessions in this symposium. Growth, doping, processing, and characterization were the major issues discussed in various sessions. Finally, interdiffusion in heterostructures was the subject of the last session.

Symposium Support: PL/NTRP and PL/LIDA.

\section{Electrochemical Synthesis Finds New Niche} (See MRS Proceedings Volume 451)

During the last 10 years, a wide range of electrochemical processes have been developed for the synthesis of novel materials and structures. Symposium P on Electrochemical Synthesis and Modification of Materials brought together for the first time at an MRS Meeting investigators from different communities to present new oppor- 
tunities and applications for electrochemical synthesis in materials science.

The focus areas for the symposium included fundamentals of film growth, electrochemical modification of surfaces, electrochemical synthesis, electrochemical deposition of metals onto semiconductors, and electrochemical deposition for magnetic and electronic applications. The symposium began with excellent presentations on in situ STM studies of metal deposition by D. Kolb (Univ. of UIm) and $\mathrm{O}$. Magnussen (BNL). F. Family (Emory Univ.) provided an overview of the evolution of morphology in electrochemical processes from dendritic to epitaxial growth. Highlights on electrochemical surface modification included presentations on surface modification through adsorption of inorganic materials (A.A. Gewirth, Univ. of Illinois), self-assembled monolayers on metal films (P.E. Laibinis, MIT), heteroepitaxial molecular films (M. Ward, Univ. of Minnesota), and derivatization of silicon surfaces (P. Allongue, CNRS). D. Lincot (Ecole Superiere) and J. Stickney (Univ. of Georgia) described epitaxial and heteroepitaxial growth of compound semiconductors. Several talks on the deposition of nanostructures illustrated many of the new applications for electrochemical techniques. N. Robertson (IBM) described new applications for electrochemical deposition in magnetic recording and E. O'Sullivan (IBM) described new opportunities for electrodeposition for MEMS devices.

Symposium Support: Solartron, Digital, TopoMetrix, and NSF.

\section{Electron Confinement Links Polycrystalline Films, Nanocrystals, and Porous Semiconductors}

\section{(See MRS Proceedings Volume 452)}

Symposium Q, Advances in Microcrystalline and Nanocrystalline Semiconductors, was the fourth in a series of MRS Fall symposia devoted to the preparation, characterization, understanding, and application of micro- and nanostructured semiconductors. A wide range of specialists shared their recent advances in three interrelated materials fields, namely: (1) nano-, micro-, and polycrystalline films; (2) semiconductor nanocrystals; and (3) porous semiconductors.

One unifying scientific theme.is common to the three fields, namely, the modification of the properties of semiconductors that results from electronic confinement. The common challenge in each of these fields, however, is to control the influence of structural features including surfaces, interfaces, grain boundaries, and intergranular phases on the properties of nano- and microcrystalline semiconduc-

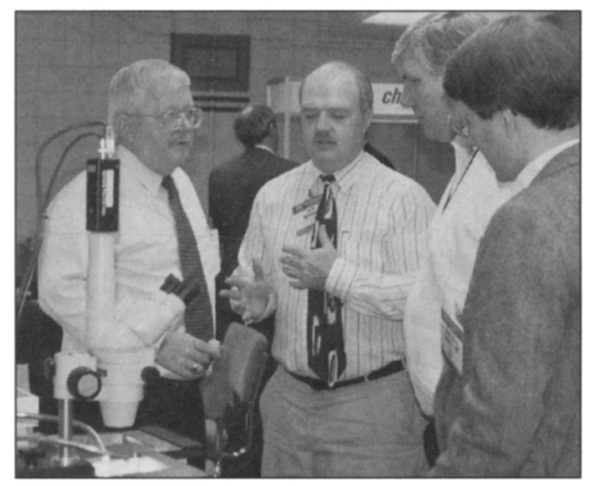

meeting with success was demonstrated with the report of device integration of Sibased LEDs (K. Hirschman, Univ. of Rochester). In addition, new applications of porous silicon continue to emerge in biotechnology (L. Canham, DRA Malvern), and in passive optical devices such as Bragg reflectors, Fabry-Pérot filters, rugate filters, and grating (M. Thonissen, KFA Julich, Germany; G. Lerondel, Univ. J. Fourier, Grenoble, France).

Symposium Support: Xerox-PARC, Hitachi, Hitachi Europe, SANYO, KANEKA, and Asahi Glass.

Exhibitors and attendees at the 1996 MRS Fall Meeting/ICEM-96 discuss the mechanics of resources for materials research.

tors. In a plenary session, excellent overviews of the current status of research in micro- and nanocrystalline semiconductor films, semiconductor nanocrystals, and porous semiconductors were provided by K. Tanaka (NAIR, Japan), L.E. Brus (Columbia Univ.), and L.T. Canham (DRA-Malvern, UK), respectively.

In the area of thin films, advanced techniques for characterizing the nucleation, growth, and structure of nanocrystalline Si films were reported based on in situ STM and ESRS (K. Tanaka, K. Ikuta, NAIR). The motivation for better understanding and optimizing such films was provided by $\mathrm{H}$. Keppner (Univ. of Neuchatel) who described a $10.7 \%$ efficient tandem solar cell made with a stable, all-microcrystalline Si bottom cell.

In the area of nanocrystal, phase transition kinetics as a function of size are providing information on the intrinsic nucleation of solid-solid-phase transformations, for example, from four-coordinate wurtzite to six-coordinate rock-sale in CdSe (C-C. Chen, UC-Berkeley). This research may lead to future approaches for chemical synthesis of a wide variety of nanocrystal of metastable phases (L. Brus, Columbia Univ.). Other studies of the optical properties of CdSe nanocrystals clearly reveal the atomic-like nature of the light-emitting state. By eliminating spectral inhomogeneities, S. Empedocles (MIT) reported a factor of 50 reduction in the photoluminescence line width (to $<120 \mu \mathrm{V}$-resolution limited-at $10 \mathrm{~K}$ ) in comparison to previous results.

In the area of porous silicon, the reported advances focused on improving control over the structure and enhancing the stability of room-temperature light-emitting materials. The fact that such advances are

\section{Range of Inorganics Share Similar Challenges}

(See MRS Proceedings Volume 453)

The technical presentations in Symposium R on Solid-State Chemistry of Inorganic Materials, although highly interdisciplinary and directed toward many different classes of solids, reflected the shared challenge to understand, control, and predict the structures and properties of inorganic solids. P.F. McMillan (Arizona State Univ.) described the high-pressure synthesis of new refractory nitride glasses harder than $\mathrm{SiO}_{2}$ with high glass transition temperatures $\left(>800^{\circ} \mathrm{C}\right)$, and high refractive indices ( 2). R.J. Cavà (Princeton Univ.) described the synthesis and structural properties of a new class of pnictide oxides, $\mathrm{Ln}_{3} \mathrm{Cu}_{4} \mathrm{P}_{4} \mathrm{O}_{2}$, some of which exhibit properties such as heavy-fermion and metallic behavior.

Appropriate doping of these compounds may lead to new superconductors. N. Setter (Lausanne, Switzerland) described state-of-the-art work elucidating structure-property relationships of microwave dielectric oxides. For a class of ordered perovskite compounds with important properties, the temperature dependence of the dielectric constant was correlated with the detailed structural arrangement. Using a mathematical examination of polarizability as a function of temperature, it was possible to make reasonable numerical predictions of dielectric constants and their temperature dependences.

Symposium Support: DuPont Central RED, Exxon Research and Engineering, Univ. of Houston, and NSF.

\section{Mesoporous Materials Expand Catalytic Conversion Possibilities (See MRS Proceedings Volume 454)}

Symposium S, Advanced Catalytic Materials, aimed to further develop the interface between progress in materials science and the field of catalysts. Catalytic materials are widely used in the oil, gas, petrochemical, and environmental industries, and are manufactured on scales of up 
to several hundred tons. Exploration and control of composition, structure, porosity, and morphology are common features with many other areas of materials science.

Mesoporous materials, in which the pores are in the 2-10 $\mathrm{nm}$ range, are currently of particular interest. Such materials may enable catalytic conversions of oil or chemical molecules which are too big to fit into microporous materials (pores up to $2 \mathrm{~nm}$ ), such as zeolites, which already find widespread application. J.Y. Ying (MIT) reported various synthetic routes to novel mesoporous transition metal oxides. An exciting possibility from this and related presentations is that a much wider range of compositions and porosities are becoming available for the catalytic chemist.

Interest in applications of advanced catalytic materials also continues to expand. Examples presented include novel borosilicate zeolites for oil refining (C.Y. Chen, Chevron); coated, sintered metal monoliths for catalytic combustion (J. Geus, Univ. of Utrecht); sol-gel modified honeycombs for electrically heated automotive catalysts (S.R. Nakouzi, Ford); and ceramic foams as catalyst supports for high temperature, short contact time catalysis (L.D. Schmidt, Univ. of Minnesota) or for photochemical destruction of volatile organics (G R. Raupp, Arizona State Univ.).

These developments in synthesis and applications continue to make advanced catalytic materials an exciting field, and further symposia are being planned.

Symposium Support: DuPont Central RED, Union Carbide, Criterion Catalyst, BP Int'l, Mobil Tech, ARCO Chem., UOP Research Center, and Shell Development Chem.

\section{Structure and Dynamics of Glasses and Glass Formers Discussed (See MRS Proceedings Volume 455)}

Glasses and Glass Formers-Current Issues, Symposium $\mathrm{T}$, provided a discussion forum for researchers from a wide variety of backgrounds who are dealing with the ubiquitous manifestations of the glassy and liquid states, and facilitated a comparison between the current ways of thinking in these various fields. Hence, the papers presented in the symposium covered a range of materials, including inorganic compounds, metals, polymers, and biomolecules. The state-of-the-art in the use of a number of methods of investigation, ranging from diffraction to dielectric and mechanical relaxation to numerical modeling, was reviewed.

An important driving force for the progress in this field is the MCT, pioneered by W. Goetze (T.U. Munich). MCT associates the characteristics of the glassy state with relaxation processes that occur in the undercooled liquid, and quantifies these processes by defining decay channels between coupled dynamical states. Developed over the last decade, this theory has prompted numerous experimental studies and computer simulations to provide confirming data. Much of the work, specifically targeted to reveal phenomena predicted by MCT, has been carried out on organic polymers.

Furthermore, significant improvements in scientific instrumentation and techniques, including a substantially more sophisticated data analysis, using computer simulations, were key to the progress in the field.

Studying the dynamic processes underlying glass formation requires probes which operate in the $\mathrm{GHz}$ to $\mathrm{THz}$ regime. Dielectric relaxation spectroscopy has long been the technique of choice for many scientists, but only recently has it been possible to carry out measurements at such high frequencies. K. Funke (Univ. of Münster) presented ionic conductivity spectra which continuously covered the range between $\mathrm{dc}$ and $\mathrm{THz}$. His results reveal a characteristic change in the conductivity dispersion near the glass transition, which can be explained with the change between the fluid- and hopping regimes of ion migration. S. Nagel (Univ. of Chicago) reported a power law dependence in the high-frequency tails of the dielectric susceptibility of undercooled liquids, with an exponent which vanishes near the glass transition.

The high fluxes generated by today's neutron sources, and the brilliance of synchrotron $x$-rays, provide much better resolution in diffraction data.

Isotope substitution and anomalous $\mathrm{x}$ ray scattering allow for the determination of partial correlations between different atomic species. D. Price (ANL) illustrated how these techniques can be combined to reveal information about the intermediate and extended-range order in inorganic network glasses. M. Gibson (Univ. of Illinois) proposed a scheme of three-atom correlations to interpret the speckle patterns produced by dark-field electron imaging, and to gain further insight into the medium range order of amorphous structures.

NMR measurements have matured over the recent past, and are regarded as one of the most powerful techniques for studying glasses for both the characterization of structure and dynamics. J. Zwanziger (Indiana Univ.) demonstrated the power of 2-D NMR for the structural characterization of borate and tellurite glasses, while S. Sen (Stanford Univ.) illustrated how this technique can be used to study ionic transport. Incoherent neutron scattering is an established technique for the study of $\mathrm{THz}$ phenomena. J. Wuttke (Univ. of Munich) showed how this technique can be combined with depolarized light scattering and field gradient NMR.

The effects of specimen size on the glass transition has been studied on ultrathin polymer films. J. Dutcher (Univ. of Guelph) found that $T_{\mathrm{g}}$ decreases linearly with film thickness, as revealed by Brillouin scattering, while D.B. Hall (Northwestern Univ.) reported a broadening of the relaxation time spectrum, but no significant change in $T_{g}$.

Atomic scale simulations for the modeling of glasses and liquids has always required large simulation ensembles. Hence, the description of atomic interactions was limited to empirical models. With the increase in computer performance, these models have become more sophisticated, and the simulations more accurate. P. Madden (Oxford Univ.) showed how the network structure in simulated silica glass is affected by taking charge polarization of strongly ionic species into account. P. Poole (Univ. of Western Ontario) used molecular dynamic simulations to demonstrate the nature of liquid-liquid phase transformations.

Another exciting finding occurred recently with the discovery of complex multicomponent alloys, which can form bulk metallic glasses without requiring excessive cooling rates. W. Johnson (Caltech) gave a detailed account of structural and dynamic properties of the $\mathrm{Zr}-\mathrm{Ti}$ $\mathrm{Ni}-\mathrm{Cu}$-based systems.

H. Frauenfelder (LANL) illustrated important analogies between the relaxation in glass-forming liquids and the folding processes of protein molecules. NIST.

Symposium Support: ONR, NSF, ARO, and

\section{Surface Modification Important for Biocompatibility}

(See MRS Proceedings Volume 456)

Symposium U, Enabling Biomaterials Technologies-Molecular StructureProperties Relationships, covered topics on the control of bulk and surface properties of biomaterials and biologically inspired materials. Various techniques of surface modification were utilized to control interaction between implantable devices and tissues. Examples include plasma-enhanced, chemical modification using self-assembled monolayers, ionbeam etching, and pulsed-laser deposition. Common applications for the techniques and biomaterials developed 
include corneal wound healing, orthopedic implants, gels for use in kidney failure, and lung surfactant proteins for respiratory distress syndrome. There is also a research initiative to develop novel biomaterials utilizing molecularly designed functional structures by the research group of S.I. Stupp (Univ. of IllinoisUrbana). Molecular design was used to develop new biomaterials with improved control of tissue-biomaterial interactions. Symposium $U$ also covered topics on development of biomimetic pathways to develop ceramic-polymer composites. Biomineralization was commonly cited to develop such composites with morphology organized at the micrometer- and nanometer-length scales.

Symposium Support: Genentech.

\section{Symthesis and Processing Methods Developed and Modeled for Nanophase/Nanocomposite Materials (See MRS Proceedings Volume 457)}

Symposium V, Nanophase and Nanocomposite Materials, was highlighted by both new developments in the field as well as advancements in established research programs that were presented in the initial symposium in 1992. In addition to new synthesis techniques, the nanophase/ nanocomposite community has developed fundamental and practical approaches to postsynthesis processing such as consolidation/sintering or dispersion as well as the identification of new property enhancements. Also included was a session devoted to computer simulation and empirical modeling of both processing and properties of nanostructured systems. The application-oriented presentations included mechanical property enhancements of metals and ceramics, magnetic cooling, sensing, drug delivery and diagnostics, catalysis, and a new development in high-heat transfer nanofluids.

Symposium Support: ONR and Nanophase Tech.

\section{Interfacial Engineering Improves Material Performance}

\section{(See MRS Proceedings Volume 458)}

Whereas in the past, symposia at MRS have focused on the structure and properties of interfaces with emphasis on understanding this structure at the atomic level, Symposium W, Interfacial Engineering for Optimized Properties, emphasized the modification or engineering of interfaces to improve overall material performance. The main topics included ways to design interfaces, the relationship between the structure and properties of the interfaces, methods of interface characterization, the mechanical properties of interfaces, interfaces in composites, and

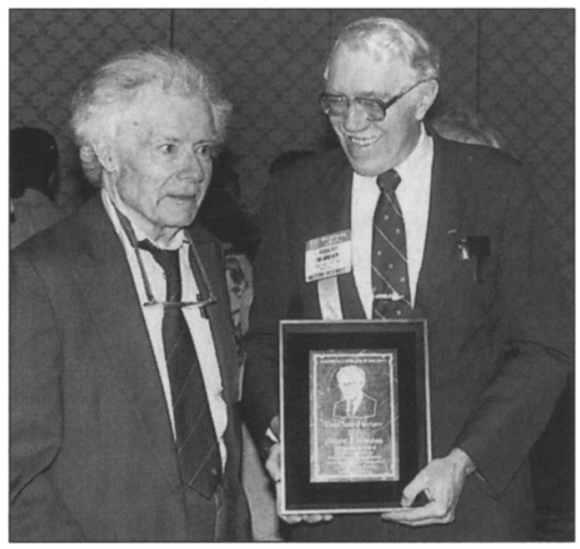

satility of EBSP in solving a number of interface-related problems.

The field of interface engineering has clearly been significantly impacted by the many new methods of interfacial characterization, and much progress has been made in relating the results of these methods to fundamental materials properties. In addition to EBSP, structural and electronic characterization methods, many based on electron spectroscopy or imaging at the atomic scale in the TEM, were presented which described the properties of interfaces in metals, ceramics, and composites in much greater detail than seen previously. In addition, new methods of data analysis, such as multivariate statistical analysis, have been applied to enhance the interpretation of the results. In addition to these nanoscale tools, other methods were presented for characterizing and testing the mechanical properties of interfaces at a more macroscopic level, including nanoindentation, $\mathrm{x}$-ray tomography, and specialized composite and thin-film interfacial properties tests.

One final area of great interest was in the field of composites where attention continues to be focused on the interface between the fiber and the matrix. Several papers addressed the mechanics of this problem and presented methods of determining interfacial strength. Also of concern was the degradation of the interface that results from reaction between the fibers and matrix, the use of coatings on the fiber to prevent this degradation, and methods to improve creep resistance of these materials.

Symposium Support: ORNL, Gatan, GE: Physical Metallurgy Lab., GE: Materials Characterization $L a b$., Univ. of Minnesota CIE, and LLNL. ing of interfaces.

One area that received significant attention in subsequent sessions was the crystallographic nature of grain boundaries and interfaces, as defined by the grain misorientation and the grain boundary orientation, and the relationship between this nature and the performance of a material. It has been known for some time that the nature or structure of an interface affects the tendency of that boundary to undergo such processes as corrosion or fracture, but two new factors have renewed excitement in this area. The first is the development of new tools to measure large sets of interface characteristics, particularly EBSP analysis in the SEM. The second is the realization that materials can be processed so that the number of boundaries with good properties can be optimized; examples showed this improvement in corrosion and creep performance of materials. In addition a number of papers showed the great ver-

\section{Smart Materials Respond to Sense (See MRS Proceedings Volume 459)}

Smart systems constitute a special class of devices that can both sense a change in the environment and respond to that change in a useful way. Central to the operation of smart systems are materials that can serve as sensors and actuators such as shape memory, piezoelectric, and magnetostrictive materials. Symposium Y, Materials for Smart Systems, addressed fundamental materials issues related to smart systems.

In the piezoelectrics section, several major themes emerged. First, as pointed out in the Turnbull lecture by Robert $\mathrm{E}$. Newnham (The Pennsylvania State Univ.), the presence of multiple phase transformations is a common thread found in all families of actuator materials. The manipulation of these transformations to develop highly active ferroelectric 
actuator materials, including materials with high electromechanical coupling coefficients, was then discussed in several talks.

A second focus revolved around the influence of mobile twin domain walls in affecting the electrical and electromechanical response of ferroelectric perovskites under a variety of loading conditions. Third, several papers were given on recent developments in thin-film actuators for integrated silicon micromachined devices and for integrated optical fiber devices.

Finally, the development of polymeric actuators was discussed. The session on magnetostrictive materials and applications covered both high strain materials and amorphous magnetostrictive materials. Several papers focused on bulk Terfenol-D, a high magnetostriction room-temperature material. The discussions on Terfenol-D centered around its use in high-power transducers and actuators as well as the development of Terfenol-D/epoxy composite materials. Several papers covered the recent progress in the development of giant magnetostrictive thin films with large strains for microsystem applications. Papers in the area of amorphous magnetostrictive materials ranged from their uses in remote sensors to utilizing the strong nonlinear behavior of these materials to manipulate chaos. Finally, the giant magnetic strain in magnetic shape memory alloys was discussed.

New trends in SMA may be summarized in the following three categories. The first is the composites, which consist of SMA-polymer, SMA-TiC, or SMA-metal. They may be used to change elastic constants in a wide range by adjusting temperature or to strengthen metals by SMA fibers. They are useful in space technology. The second is TiNi thin films, which are potential materials for micromachines. Such fine-grained films are now fairly easy to make by sputter deposition.

However, several problems are present on the uniformity in composition and on the control of the composition since the transformation temperatures are very sensitive to composition. The constraint from the substrate and the difference in thermal expansion is another problem, which may become serious during functioning when the films are made on $\mathrm{Si}$ chips. In the third category, new developments in SMAs were discussed in detail, which include computer simulation of microstructure evolution, a new thermodynamic approach to martensitic transformations, incommensurability, rubberlike behavior, and application of R-phase that enables the linear control in thermostatic valves.

In addition to the work on shape memory, magnetostrictive, and piezoelectric actuators, one session was dedicated to a discussion of alternative sensing and actuating mechanisms. Materials for gas sensors, electrochromic devices, magnetorheological fluids, and thermoplastic elastomers were described.

Symposium Support: Furukawa Electric, PIO$L A X, A R O$, and ORNL.

\section{Microstructure Key to Intermetallic Behavior}

(See MRS Proceeding Volume 460)

In Symposium Z on High-Temperature Ordered Intermetallic Alloys, the study of titanium aluminides has been focused on understanding and developing a structure/properties/processing correlation for two-phase $\mathrm{TiAl} / \mathrm{Ti}_{3} \mathrm{Al}$ alloys. It has become clear that the control of microstructure is more important than the control of alloy composition of $\mathrm{TiAl}$ alloys for property improvement. Both experimental and modeling work indicates that the tensile ductility at ambient temperatures and the strength at ambient and elevated temperatures for two-phase TiAl alloys with full lamellar structures can be substantially improved by refining grain size and interlamellar spacing. TiAl alloys with controlled microstructure and alloy composition showed more than $5 \%$ of tensile elongation at room temperature and close to $1000 \mathrm{MPa}$ of the yield strength at $800^{\circ} \mathrm{C}$. $\mathrm{M}$. Loretto (Birmingham Univ.) reported the development of a TiAl alloy with a room-temperature strength of more than $1000 \mathrm{MPa}$ and a tensile ductility larger than $1 \%$ in as-cast conditions. TiAl alloys generally have good oxidation resistance at temperatures up to $800^{\circ} \mathrm{C}$ in air, but lose their oxidation resistance at higher temperatures. Another development reported is that the coating of TiAl alloys with $\mathrm{TiAl}_{3}$-based materials dramatically improves their oxidation resistance at temperatures up to $1000^{\circ} \mathrm{C}$. This indicates the possibility of using $\mathrm{TiAl}$ alloys at that high temperature.

The effects of solute content, processing, and heat treatment on microstructure and properties of iron aluminides were emphasized in several papers. J. Liu (Xian Univ.) reported that large additions of $\mathrm{Mn}$ to $\mathrm{Fe}_{3} \mathrm{Al}$ produces an fcc-ordered precipitate that increases the impact energy of binary $\mathrm{Fe}_{3} \mathrm{Al}$ by up to three times. This observation is noteworthy in that impact resistance of $\mathrm{Fe}_{3}$ alloys with reasonably high ductility (in tensile tests) is low at room temperature, and is not improved at higher temperatures.
Relatively new processing techniques for intermetallics include oxide-dispersionstrengthened $\mathrm{FeAl}$ alloys made from powders, nanocrystalline $\mathrm{TiAl}$ alloys made by ball milling of powders, and plasma spraying to produce either coatings or monolithic structures. H. Herman (SUNY-Stony Brook) described the plasma spray process and showed examples of several intermetallics, including aluminides and silicides, made by spraying of powders. This technique also lends itself to the production of fibrous and lamellar composites. Another processing technique that appears to be promising for production of very high strength composites is unidirectional solidification of eutectic composites. This technique, which had been utilized extensively in the 1970s and 1980s, is now being used by B. Bewlay (GE) to produce composites based on Laves phases such as $\mathrm{Cr}_{2} \mathrm{Nb}$ or niobium silicide-based composites with high-temperature creep strengths comparable to those of single-crystal superalloys. A. Misra et al. (Univ. of Michigan) are using the same technique to produce NiAl-based composites. Rhenium was shown to improve fracture toughness of $\mathrm{NiAl}-\mathrm{Mo}$ eutectics and to improve strength of $\mathrm{NiAl}-\mathrm{Cr}$ eutectics without loss of toughness. M. Nazmy (ABB-Baden) and coworkers at Rensselaer Polytechnic Institute reported an alternative method to improve toughness of silicides. In that work, platinum alloy fibers are being incorporated into a $\mathrm{Cr}_{3} \mathrm{Si}$ matrix by hot pressing in an effort to produce ductile phase toughening without sacrificing oxidation resistance. Oxidation resistance is shown to be very good, unlike previous work in which ductile refractory metal fibers such as niobium or tungsten have severely degraded oxidation resistance of $\mathrm{MoSi}_{2}$.

V. Sikka (ORNL) reported on the commercialization status of alloys based on $\mathrm{Ni}_{3} \mathrm{Al}$. Cast components of alloy IC $221 \mathrm{M}$ are being produced in large quantities by several commercial organizations for applications such as heat treatment fixtures and forging dies. However, several areas of needed research were described, including improvement of compressive strength and determination of long time creep resistance.

While considerable attention is still being devoted to a basic understanding of deformation mechanisms in intermetallics, the field has matured to the point where processing and heat treatment innovations are supplanting alloy development approaches to improved properties. However, research continues to lag in key areas such as impact properties, fatigue behavior, and oxidation resistance.

Symposium Support: ORNL. 
Complex Systems Understood through Combined Neutron and X-Ray Analysis

In Symposium CC, Neutron and X-Ray Scattering Studies of Materials, a wide range of problems were presented in sessions on superconductivity, magnetism, complex systems, and kinetics.

In the first session several papers were presented that dealt with correlated electron systems, and more specifically high- $T_{c}$, and unconventional superconductors. Of particular interest were the discussions on the novel magnetic resonance peak observed in the $\mathrm{YBa}_{2} \mathrm{Cu}_{3} \mathrm{O}_{6+x}$ superconductor, and the studies of charge and spin stripe correlations in the cuprates and nickelates.

Results presented on magnetism demonstrate the importance of magnetic $x$-ray scattering techniques for the study of surface magnetism. Of particular interest were the studies on the uranium oxide (001) surface and on $\mathrm{CO}_{3} \mathrm{Pt}(111)$ which revealed subtle differences between surface and bulk magnetism in these materials.

Three sessions devoted to the study of complex systems by $x$-ray and neutron scattering techniques demonstrate the increasing importance of these techniques for the study of complex systems with interesting physical properties. It is practically impossible to outline in a brief summary the enormous amount of information contained in the papers presented in these sessions. It is becoming, however, clear that an understanding of complex systems necessitates the combination of both $x$-rays and neutron scattering investigations. In particular, reflectivity and small angle studies both with neutrons and $x$-rays are becoming powerful tools for the study of these systems. Of particular interest were the reflectivity studies of protein resistance surfaces, charged Langmuir monolayers, thin films, and Langmuir block copolymer monolayer. Examples of combined x-ray and neutron small angle scattering studies were presented.

The results presented in the area of kinetics demonstrate the importance of x-ray scattering techniques in the investigations of the kinetics of various physical and chemical processes. Of particular interest was the application of inelastic $x$-ray scattering techniques to the study of collective excitations of liquid water. This is a first step toward the application of $x$-rays in the study of collective excitations in bulk matter, presently the exclusive domain of neutron spectroscopy. A description of a freeelectron laser hard $\mathrm{x}$-ray source was also presented as well as a description of the spin-echo spectrometer at NIST.

Symposium Support: BNL, Iowa State Univ., $A N L$, and $O R N L$

\section{Artillery, Medical Instruments Among Archaeological Items Analyzed (See MRS Proceedings Volume 462)}

Organized by the Getty Conservation Institute, Smithsonian Institution, University College, and Parks Canada, Materials Issues in Art and Archaeology (Symposium DD) represented a wide diversity of disciplines due to an even wider range of materials, technologies, and conservation challenges they present to the modern investigator. Highlights include a look at two unique metallurgies, that of early European artillery and ancient medical instruments. Other papers on metallurgy examined the technology of historical lead and silver production, bronze punic coins, metal nails, and a gold hoard from late Roman/Early Byzantine period Jordan. Ancient and historical metallurgy was followed by two sessions covering natural and artificial glasses as well as ceramics. These papers presented evidence for long-distance obsidian trade in Indonesia, analysis of opaque Renaissance glass, and production of ceramics ranging from Mexico, China, Turkey, Malaysia, and Sardinia.

Papers on analytical techniques applied to historic materials produce a host of fascinating results and interpretations especially when compared to older methods of analysis. Prevelant this year were papers that used neutron activation analysis on Chinese porcelains, Mid-ir spectroscopy to help identify museum plastics, ICP-MS on archaeomaterials, PIXE, and scanning Auger spectroscopy.

Interest among large national laboratories in helping to address issues in preservation has grown in recent years.

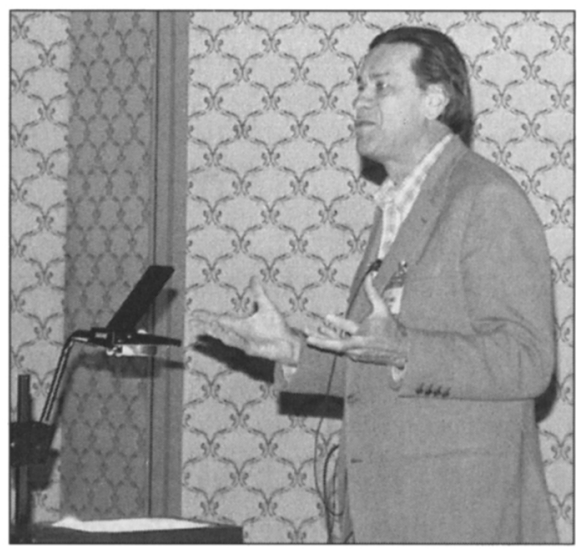

Nobel Laureate Pierre-Gilles de Gennes of College de France presents a talk for the Frontiers of Materials Research (Symposium $X$ ) on the reflection on the evolution of polymer materials.

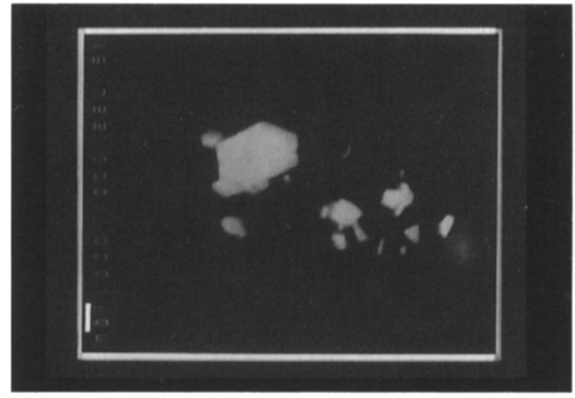

A backscattered electron micrograph of lead antimonate particles in a yellow opaque Roman glass containing 5.0 $w t \%$ lead oxide (the scale bar is $1 \mu \mathrm{m}$ ).

J. Brinker's group at Sandia National Laboratory has been funded to examine protective strategies for the protection of calcareous building stone. This group presented a paper on the use of passivating coupling agents to reduce sensitivity to acid precipitation. From NASA Lewis Research Center came a paper describing the use of atomic oxygen for the removal of smoke damage to paintings.

\section{Statistical Mechanics Describes Materials and Phenomena Ranging from Granular Flow to DNA}

(See MRS Proceedings Volume 463)

The concepts of statistical mechanics have long been among the most widely applied of physical ideas. The most notable aspect of Symposium EE, Statistical Mechanics in Physics and Biology, was the range of subjects, including molecular biology, microbiology, chemical engineering, petroleum engineering, polymer science, and metallurgy.

The first two days of the symposium were dominated by biological physics. J.E. Marko (Univ. of Illinois-Chicago) and W.K. Olson (Rutgers Univ.) pointed out that the statistics of DNA molecules are subtle due to their intrinsic chirality, which causes them to twist back on themselves much like phone cords. H. Li (NEC Research Institute) discussed another biological polymer, the protein, arguing that nature has chosen protein structures which fold particularly easily compared to random polymerizations of amino acids. Speakers then turned from molecular to microbiology, with J.A. Shapiro (Univ. of Chicago) discussing the remarkable patterns formed by swarming proteus colonies, and S. Leibler (Princeton Univ.) discussing the mechanics associated with cell division.

P.G. de Gennes (College de France) introduced a discipline and a length scale in his well-attended lecture on granular 

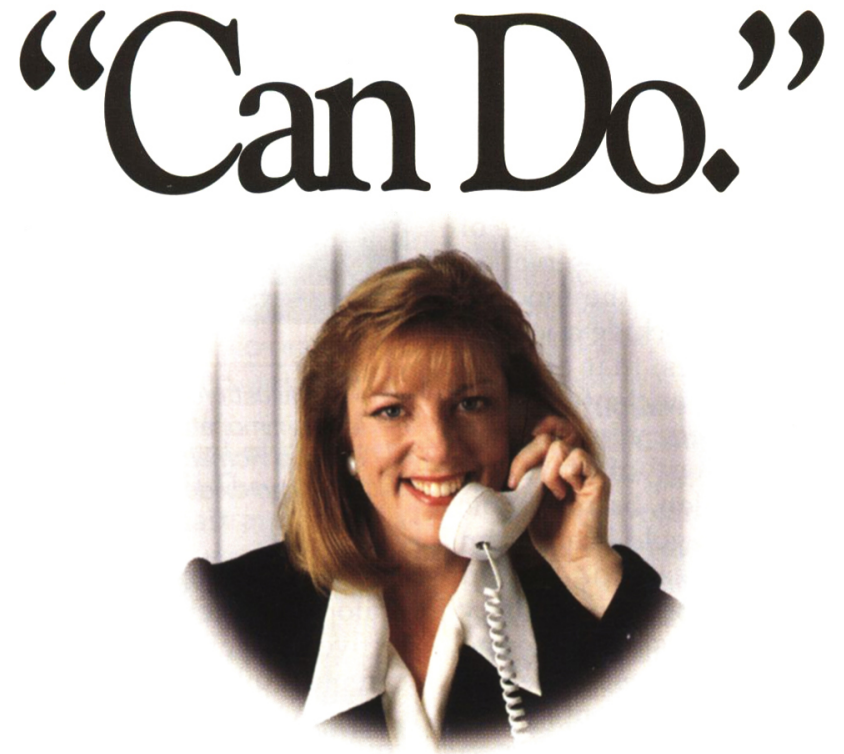

\section{Whatever You Need in Inorganics - We'll Work With You to Make It Happen.}

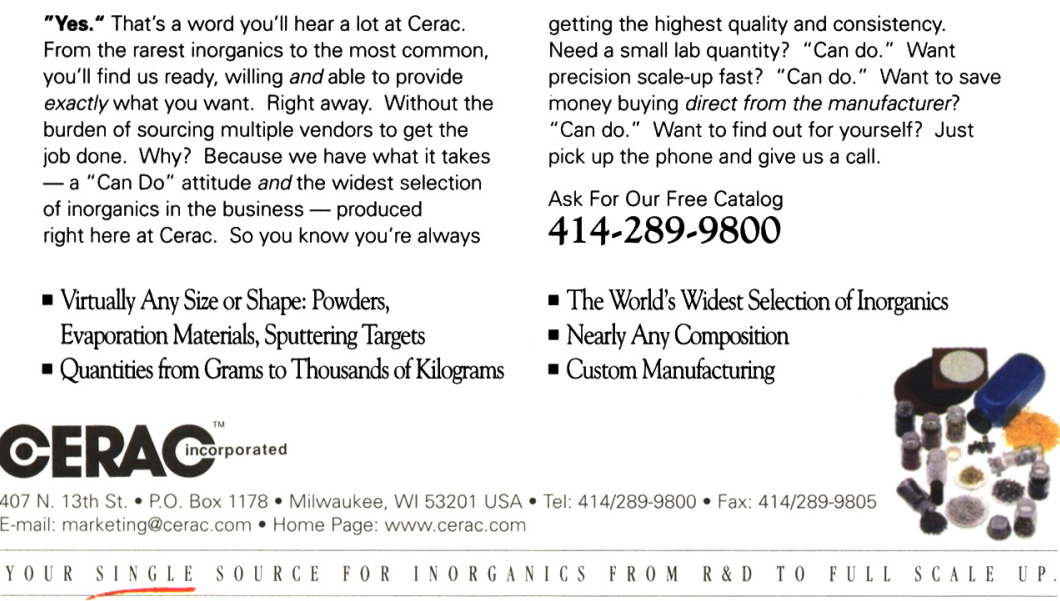

Circle No. 9 on Reader Service Card. cuprate superconductors relevant for utilization of these compounds in a variety of applications.

Thin-film studies shows an increased effort to achieve control over the structure at an atomic level. While most of this work employs $\mathrm{MBE}$, notable results are also obtained using sophisticated laser ablation systems equipped with in situ surface monitoring tools such as RHEED. Improved films provided for greatly improved electronic devices such as ramp Josephson junctions (H. Rogalla, Univ. of Twente, Netherlands) and SQUIDs (J. Clarke, UC-Berkeley). A successful synthesis of the first high- $T_{c}$ SIS tunnel junctions was also reported (J.N. Eckstein, Varian).

Several groups used atomic-layer engineering and epitaxial stabilization to fabricate new, metastable superconductor compounds. M. Lagües (ESPCI, France) announced a successful synthesis of $\mathrm{Bi}_{2} \mathrm{Ca}_{2} \mathrm{Cu}_{2} \mathrm{O}_{5}$ with $T_{2}=53 \mathrm{~K}$. So far, all the known high- $T_{c}$ superconductors contained $\mathrm{CuO}_{2}$ planes. In contrast, this artificial new compound contains sheets which consist of $\mathrm{Cu}_{2} \mathrm{O}_{3}$ ladders. If this discovery is confirmed, this will be a new paradigm with a profound impact on theoretical understanding of high-temperature superconductivity.

Studies of synthesis, structure, and properties of bulk superconductors have also enabled significant advances in the manufacturing of practical devices such as flywheels for energy storage (W-K. Chu, Univ. of Houston) and superconducting tapes and wires for power applications. For example, fundamental studies of the statics and the dynamics of vortices (D. Nelson, Harvard Univ.; G. Crabtree, ANL, and others) have stimulated experiments where defects are deliberately created by heavy ion irradiation or insertion of insulating nanorods (P.D. Yang, Harvard Univ.). Such artificial columnar defects strongly pin vortices and provide a dramatic increase in critical currents.

\section{Cement Improvements Focus on Microstructure and Interfaces}

Portland cement concrete production worldwide is approaching $10^{9}$ tons per year, attracting much research attention: even modest improvements in performance and durability result in large economics benefit. Symposium $\mathrm{HH}$, StructureProperty Relationships in Hardened Cement Paste and Composites, emphasized the application of materials science to these outstanding concerns. One focus of the symposium was on microstructure: its characterization, development, and its rela- 


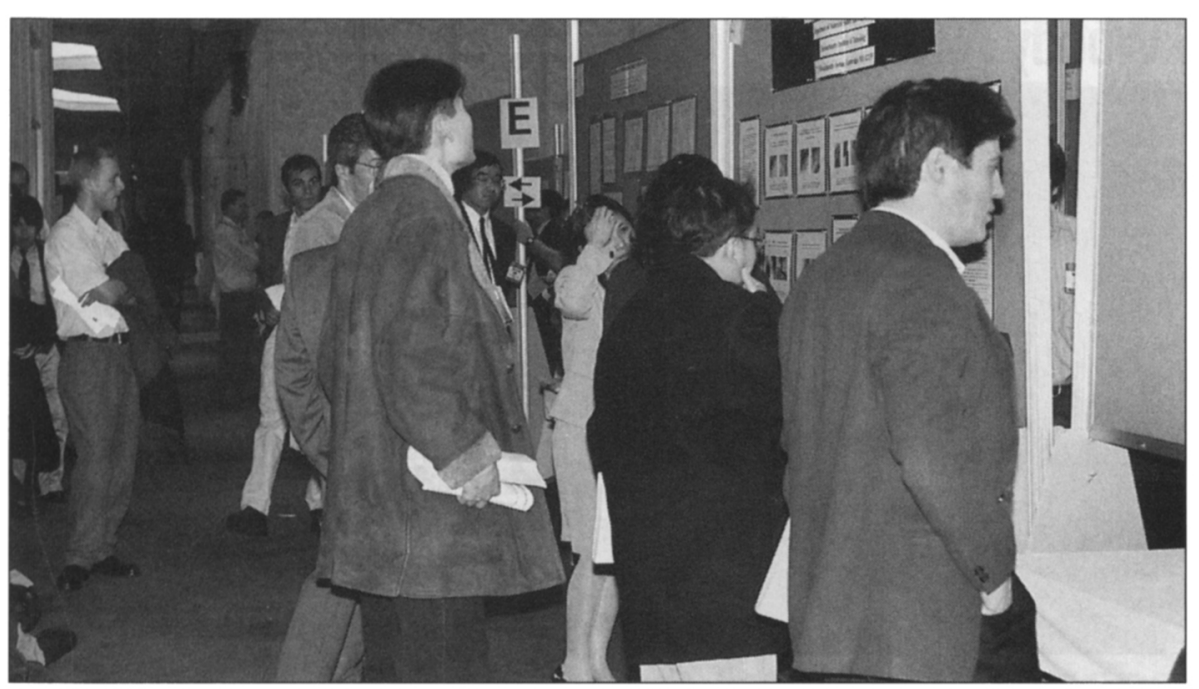

Meeting attendees view poster sessions in the evening at the 1996 MRS Fall Meeting/ICEM-96.

tion to physical properties (e.g, diffusion of aggressive ions). Permeability and transport properties of pastes and composites occupied a special session. The boundary, or interracial zone, between cement paste and embedded materials are an important contributor to diffusion potential, and stress transfer across this zone influences the mechanical properties. Fibers have been used to modify the mechanical properties and control shrinkage: carbon fibers appear to show promise.

A joint session with Symposium II on Scientific Basis for Nuclear Waste Management was also held. Cements are an important component of engineered barriers to the return of radioactive species to the biosphere. No formal publication is planned for Symposium HH but two special issues of Cement and Concrete Research and Advanced Cement-Based Materials will accommodate those authors desiring publication: papers in the joint session with Nuclear Waste Management may appear in the MRS Proceedings (Volume 465) of Symposium II.

Symposium Support: Portland Cement, Chichibu Onoda Cement, and Federal Highway Adm.

\section{Software, Curricula Ideas Shared in Materials Education Workshop}

The Workshop on Materials Education (Symposium JJ) was marked by lively and thoughtful discussions, presentations of new ideas, and impressive real-time computer-based demonstrations. The sessions on methodology of teaching opened with a tutorial by K. Constant (Iowa State Univ.) on techniques for addressing the diversity of learning styles in the interests of effective teaching. Later in the session, the audience became an eager (if somewhat self-conscious) "class" as M.A. White (Dalhousie Univ.) led them through a guided small-group exercise to self-discover how and why the photocopying process works.

Sessions on modular courseware featured many demonstrations of instructional software developed to assist both students and teachers. Attendees observed an evolving pattern where it seems the most effective software efforts will be those geared to achieve comprehensive, self-consistent, coherent sets of modules (akin to complete textbooks) in a finite time. These maximize the benefits of hyperlinks and course coordination, and the overall load on faculty authors. Such efforts require major organization and commitment of resources, with the involvement of funding agencies, publishers, and the university. Editorially, while the modular revolution is both exciting for students and theoretically a powerful learning aid, few reports were available on the quantitative assessment of this approach as an improvement in teaching efficiency. Such evaluation will surely be needed ultimately to justify the costs involved, and future authors and publishers of modules may want to incorporate assessment tools in their products.

Materials curricula at all levels were discussed in several sessions, ranging from development of specific courses to the architecture of a new, fully integrated academic experience in materials engineering constructed from the basic elements and appropriately interlinked and reinforced in higher years, as proposed by B. London (California Polytech State Univ.)

The panel discussion on the graduate materials curriculum raised several key questions for the education of MS and PhD candidates. D. Backman (GE) provided an industrial perspective, indicating that the current focus on near-term products, affordability versus performance, team orientation, globalization, and outsourcing require the graduate curriculum to provide broad exposure to associated engineering disciplines and to research carried out in the context of multidisciplinary "real world" projects. M. Flemings (MIT) and J. Narayan (N. Carolina State Univ.) provided the university perspective in terms of depth versus breadth, problembased training, and teaming up with industries to provide combined BS-M. degrees. An issue brought up by the audience was the training of graduate students who have diverse backgrounds, from engineering disciplines to chemistry and physics. One approach to this question, based on an upper-level introductory course, was later presented by R. Hummel (Univ. of Florida).

Symposium Support: IBM-Almaden.

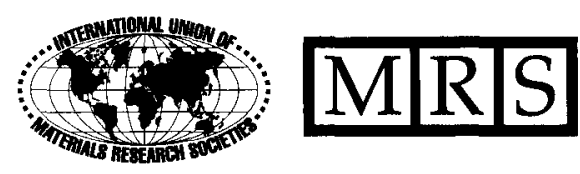

\section{URSS Spring Meeting Junior Facully For'un: Girantsminanship}

\author{
Monday, March 31, Noon-1:00 p.m. \\ Golden fiate B3, San Francisco Marriodi \\ Panel liscusssion. Box lunches will be availahle.
}

